\title{
Chapter 19 \\ Recent Advances in Seismic Soil Liquefaction Engineering
}

\author{
K. Önder Çetin and H. Tolga Bilge
}

\begin{abstract}
The assessment of cyclic response of soils has been a major concern of geotechnical earthquake engineering since the very early days of the profession. The pioneering efforts were mostly focused on developing an understanding of the response of clean sands. These efforts were mostly confined to the assessment of the mechanisms of excess pore pressure buildup and corollary reduction in shear strength and stiffness, widely referred to as seismic soil liquefaction triggering. However, as the years passed, and earthquakes and laboratory testing programs continued to provide lessons and data, researchers and practitioners became increasingly aware of additional aspects, such as liquefaction susceptibility and cyclic degradation response of silt and clay mixtures. Inspired from the fact that these issues are still considered as the "soft" spots of the practice, the scope of this chapter is tailored to include a review of earlier efforts along with the introduction of new frameworks for the assessment of cyclic strength and straining performance of coarse- and fine-grained soils.
\end{abstract}

\subsection{Introduction}

The assessment of cyclic response of soils has been a major concern of geotechnical earthquake engineering since the very early days of the profession. Engineering treatment of liquefaction-induced problems evolved initially in the wake of the two devastating earthquakes of 1964 (Niigata, Japan and Great Alaska, USA), during

\footnotetext{
K. Önder Çetin $(\bowtie)$

Department of Civil Engineering, Middle East Technical University, Ankara, Turkey

e-mail: kemalondercetin@gmail.com
}

H.T. Bilge

GeoDestek Geoengineering and Consultancy Services, Ankara, Turkey 
1. Assessment of the liquefaction of "triggering" or initiation of soil liquefaction.

2. Assessment of post-liquefaction strength and overall post-liquefaction stability.

3. Assessment of expected liquefaction-induceddeformations and displacements

4. Assessment of the consequences of these deformations and displacements.

5. Implementation (and evaluation) of engineered mitigation, if necessary.

Fig. 19.1 Key elements of soil liquefaction engineering

which seismically-induced soil liquefaction was listed as one of the prime causes of structural failures. Pioneering efforts to resolve this problem have focused on developing an understanding on liquefaction triggering behavior of mostly clean sands. However, as earthquakes continued to provide lessons and data, researchers became increasingly aware of the problems associated with the cyclic response of silty and clayey soils.

Today, the profession of "soil liquefaction engineering" is emerging as a rapidly progressing field of practice. Within the scope of this chapter, in addition to the summary of the current state of practice, recent advances in this progressing field will be presented. As illustrated schematically in Fig. 19.1, consistent with the five major steps of seismic soil liquefaction engineering assessment, the discussion layout of the chapter is also structured to follow the same footprints.

Among these, the first step in seismic soil liquefaction engineering involves the assessment of soil liquefaction triggering and has drawn the highest level of research interest. Despite the level of current controversy, it can still be concluded as the most developed assessment stage in liquefaction engineering, and will be discussed next.

\subsection{Assessment of Liquefaction Potential and Triggering}

\subsubsection{Potentially Liquefiable Soils}

There has long been a consensus in the literature that "clean" sandy soils, with limited fines, are potentially vulnerable to seismically-induced liquefaction. There has, also been significant controversy and confusion regarding the liquefaction potential of silty soils (and silty/clayey soils), and also of coarser, gravelly soils and rockfills.

The cyclic behavior of coarse, gravelly soils is not very different than that of "sandy" soils. There are now a number of well-documented field cases of 
liquefaction of coarse, gravelly soils (e.g.: Ishihara 1985; Evans 1987; Harder 1988; Andrus et al. 1991). As discussed in Seed et al. (2001), these soils do differ in behavior from sandy soils in two ways: (1) they can be much more pervious, and so can often rapidly dissipate cyclically generated pore pressures, and (2) due to their larger particle masses, the coarse gravelly soils are seldom deposited "gently" and so they are not commonly encountered in loose state as compared with sandy soils. However, it should be noted that the apparent drainage advantages of coarse, gravelly soils can be eliminated (i) if they are surrounded and encapsulated by less pervious finer materials, (ii) if drainage is internally impeded by the presence of finer soils in the void spaces between the coarser particles, or (3) if the layer thickness is large, which in turn increase the distance over which drainage must occur (rapidly) during an earthquake. In these cases, the coarser soils should be considered to be potentially liquefiable and be assessed for liquefaction triggering hazard. This naturally requires the estimation of in-situ density state (or the penetration resistance), for which the Becker penetration test still continues to be the only practical tool, despite its major limitations.

Contrary to the consensus on liquefaction potential of clean sands, the susceptibility of silt and clay mixtures to liquefaction has been one of the controversial and widely discussed issues. As previously stated, in the early days of the profession, plastic silt and clay mixtures were considered to be resistant to cyclic loading, and consistently, most research was focused on cyclic response of saturated sandy soils mainly. This choice is also reinforced with liquefaction-induced ground failure case histories at coarse-grained (sandy) soil sites after the 1964 Alaska and Niigata earthquakes. However, in the following years, especially after fine-grained soil site failure case histories of 1975 Haicheng and 1979 Tangshan earthquakes from China (Wang 1979), increasing number of research studies focused on understanding their cyclic response.

On the basis of Wang's (1979) database and conclusions, a set of criteria to assess liquefaction potential of soils with fines (widely referred to as Chinese Criteria) was proposed by Seed and Idriss (1982). These criteria had been used widely with slight modifications (Finn et al. 1994; Perlea 2000; Andrews and Martin 2000). More recently, ground failure case histories compiled after 1989 Loma Prieta, 1994 Northridge, 1999 Adapazari and Chi-Chi earthquakes have refreshed research attention on assessing cyclic mobility response of clayey soils. Case histories from these earthquakes highlighted that low plasticity silt and clay mixtures may significantly strain soften, which may in turn cause significant damage to overlying structural systems. As an alternative to Chinese Criteria, Seed et al. (2003), Bray and Sancio (2006), Boulanger and Idriss (2006), and Bilge (2010) proposed new susceptibility criteria based on field observations and laboratory test results. Before the discussion of these methods, it is helpful to note that assessing susceptibility of soils to liquefaction, requires a potentially liquefiable soil definition, which ideally should be independent of the intensity and duration of earthquake loading. This is a difficult to achieve requirement and is listed as one of the common drawbacks of existing susceptibility criteria. Hence, in practice, for most cases, unfortunately liquefaction susceptibility (potential) assessments are combined with liquefaction triggering. 
Fig. 19.2 Criteria for liquefaction susceptibility of fine-grained sediments proposed by Seed et al. (2003) (After Seed et al. 2003)

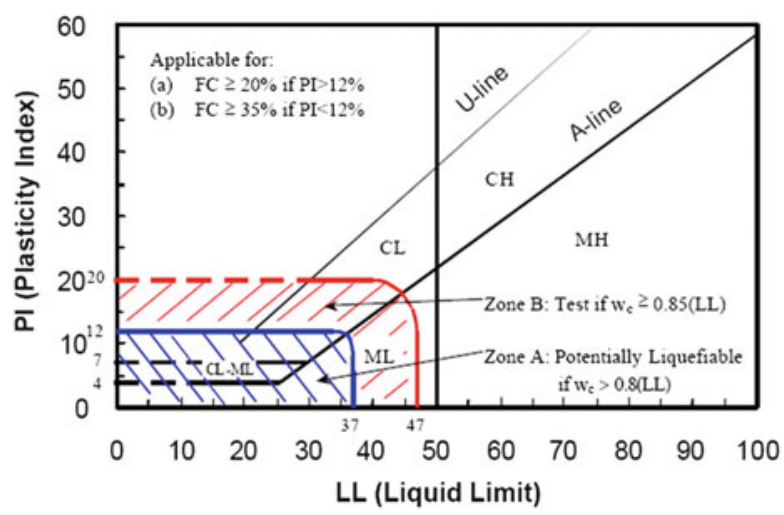

Fig. 19.3 Criteria for liquefaction susceptibility of fine-grained sediments proposed by Bray and Sancio (2006)

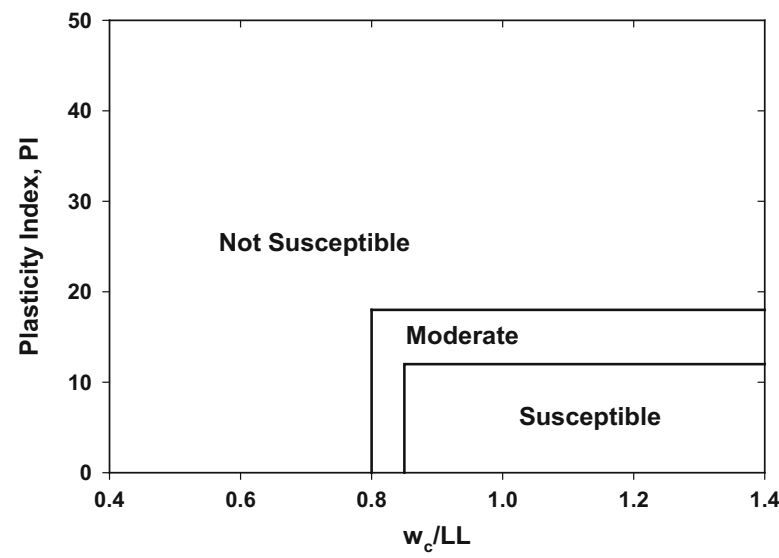

Seed et al. (2003) recommended a set of new susceptibility criteria inspired from the case histories and results of cyclic tests performed on "undisturbed" finegrained soils documented after 1999 Adapazari and Chi-Chi earthquakes. As presented in Fig. 19.2, Seed et al. (2003) used liquid limit (LL), plasticity index (PI) and water content (w) to assess liquefaction susceptibility of soils. Fine grained soils with $\mathrm{PI} \leq 12$ and $\mathrm{LL} \leq 37$ are concluded to be potentially liquefiable, if the natural water content is wetter than $80 \%$ of their liquid limit.

Bray and Sancio (2006) developed their liquefaction susceptibility criteria based on cyclic test results performed on undisturbed fine grained soil specimens retrieved from Adapazari province of Sakarya City, in Turkey. As summarized in Fig. 19.3, contrary to Seed et al. (2003), Bray and Sancio adopted the PI and w/LL ratio as the two input parameters of the problem. Fine grained soils with $\mathrm{PI} \leq 12$ are judged to be potentially liquefiable, if their natural water content is wetter than $85 \%$ of their liquid limit. Also, it should be noted that unlike most of available methods to assess liquefaction susceptibility of fine grained soils, Bray and Sancio (2006) provided a complete documentation of their database (i.e. tested specimens and also 
Fig. 19.4 Criteria for differentiating between sand-like and clay-like sediment behavior proposed by Boulanger and Idriss (2006) (After Boulanger and Idriss 2006)

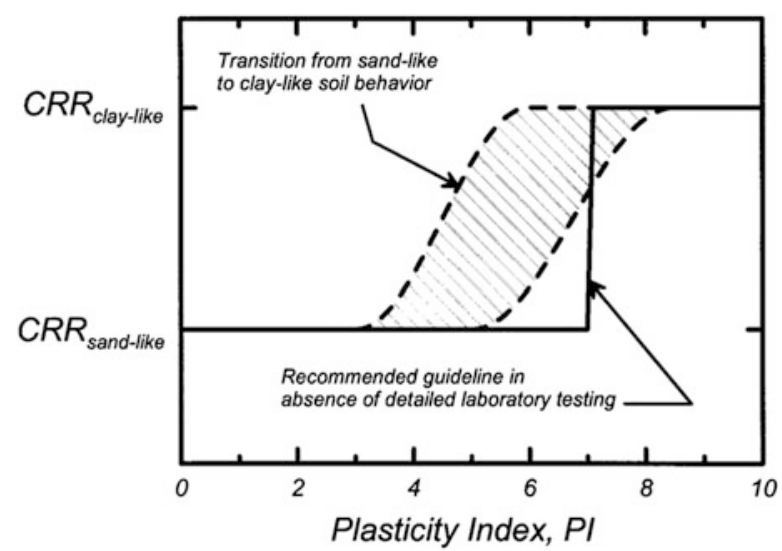

test conditions), which establish the basis of their recommendation. As clearly revealed by the adopted cyclic stress ratio levels and consolidation stress histories of soil samples, the intent of these criteria seems to assess liquefaction potential (better to refer to it as triggering) response of Adapazari soils, specifically subjected to 1999 Kocaeli Earthquake $\left(\mathrm{M}_{\mathrm{w}}=7.5\right)$ shaking. This limits the global validity of their findings.

Again, a relatively recent attempt was made by Boulanger and Idriss (2006) based on cyclic laboratory test results and on their extensive engineering judgment. As part of this new methodology, cyclic response of fine-grained soils are categorized as "sand-like" and "clay-like", where soils that behave "sand-like" are judged to be potentially liquefiable and have substantially lower values of cyclic resistance ratio (CRR) compared to those classified as to behave "clay-like". As presented in Fig. 19.4, the only input parameter was chosen as PI, and fine grained soils with PI $>7$ are judged to exhibit significantly "larger" cyclic resistance. The main drawback is that the y-axis of Fig. 19.4 is not to scale, thus the magnitude of larger CRR of "clay-like" soils as compared to "sand-like" ones cannot be clearly appreciated. Moreover, it should be noted that CRR definitions of the authors for "sand like" and "clay like" soils are quite different; hence a direct and a fair comparison between them is difficult.

As part of his Ph.D. studies under the supervision of Prof. Cetin, Bilge (2010) proposed a new liquefaction susceptibility criterion based on cyclic triaxial tests performed on a wide range of high quality "undisturbed" fine grained soil samples. As opposed to a $r_{u}$ or $\gamma_{\max }$ threshold, occurrence of contraction - dilation cycles (i.e. banana loops), was used as the screening evidence for liquefaction triggering. Fine grained soils with PI values in excess of 30 are identified as "non-liquefiable" but with susceptibility to "cyclic mobility". Similarly, fine grained soils satisfying the following condition are classified as potentially "liquefiable" 
Fig. 19.5 Proposed liquefaction susceptibility criterion

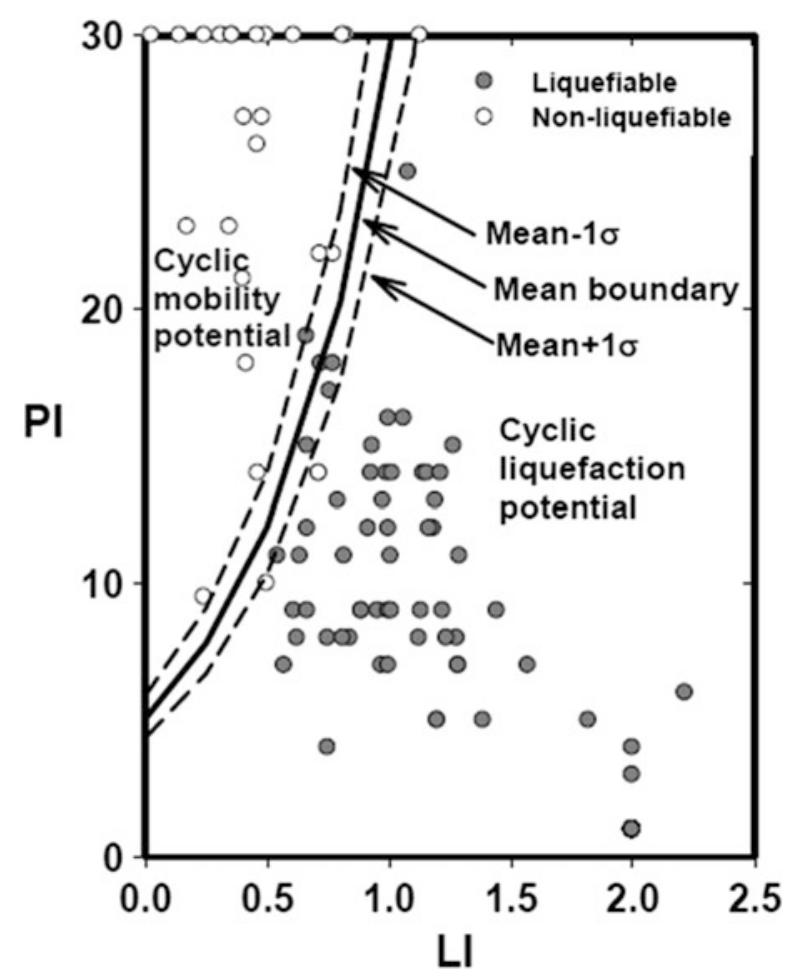

$L I \geq 0.578 \cdot \ln (P I)-0.940$

where LI is the liquidity index. The use of LI along with the occurrence of banana loops as a screening tool could be listed as the major contribution of this method. The proposed criterion along with the test database is presented in Fig. 19.5, and a complete documentation is available in Bilge (2010).

Although these studies were welcomed by practicing engineers as significant improvements over earlier efforts, they were observed to suffer from one or more of the following:

(i) ideally separate assessments of (a) identifying potentially liquefiable soils and (b) liquefaction triggering, were combined into a single assessment. When soil layers (in the field) or samples (in the laboratory) liquefied under a unique combination of CSR and number of equivalent loading cycle, $\mathrm{N}$ (or moment magnitude of the earthquake), they were erroneously labeled as "potentially liquefiable" rather than correctly labeled as "liquefied" at the selected CSR and $\mathrm{N}$ combination. These types of combined assessment procedures produce mostly biased classifications of potentially liquefiable soils.

(ii) judging liquefaction susceptibility of a soil layer or a sample through a unique combination of CSR and number of equivalent loading cycle (or moment 
magnitude of the earthquake) requires clear definition for liquefaction triggering. Unfortunately, there exist multiple and mostly conflicting strain, pore pressure or field performance based definitions, some of which are not even clearly documented.

(iii) liquefaction triggering manifestations and their extent are not unique in the field (sand boils, extensive settlements, lateral spreading etc.). There is no single liquefaction definition (exceedance of threshold $r_{u}$ or $\gamma_{\max }$ levels) for laboratory-based evaluations either. The success rate of the existing assessment methodologies for identifying liquefiable soils depend strongly on the adopted threshold levels.

The authors of this chapter believe that either fine or coarse grained, every soil can be liquefied, and hence potentially liquefiable, if liquefaction triggering is defined by a threshold maximum shear strain, excess pore pressure ratio, or even the existence of banana loops. The dilemma, which is yet to be solved, is the identification of cyclic stress and number of loading cycle combinations to trigger liquefaction. Hence, with increasing popularity in performance based design practice, and available tools to assess cyclic straining and pore pressure responses of both fine and coarse grained soils, the elementary assessment steps of liquefaction susceptibility and triggering will be less popular and eventually eliminated. Alternatively, the assessments will directly start with the estimations of cyclicallyinduced strain or excess pore pressure levels. However, until this is achieved, existing liquefaction susceptibility and triggering methodologies will be used as initial screening tools.

\subsubsection{Assessment of Liquefaction Triggering}

Quantitative assessment of the likelihood of "triggering" or initiation of liquefaction is the necessary first step for most projects involving seismically-induced liquefaction problems. There exist two approaches for the purpose: the use of (1) laboratory testing of "undisturbed" samples, and (2) empirical relationships based on correlations with observed field behavior on the basis of various in-situ "index" tests.

The use of laboratory testing is complicated by difficulties associated with sample disturbance during both sampling and reconsolidation of cohesionless soils. It is also difficult and costly to perform high-quality cyclic simple shear testing, and additionally cyclic triaxial testing poorly represents the loading conditions of principal interest for most seismic problems. Both sets of problems can be ameliorated, to some extent, by use of appropriate "frozen" sampling techniques, and subsequent testing in a high quality cyclic simple or torsional shear apparatus. The difficulty and cost of these sophisticated techniques, however, places their use beyond the budget and scope of most engineering projects. 
Accordingly, the use of in-situ "index" testing is the dominant approach in common engineering practice. As summarized in the recent state-of-the-art paper (Youd et al. 2001), four in-situ test methods have now reached to a level of sufficient maturity as to represent viable tools for this purpose. These are (1) the standard penetration test (SPT), (2) the cone penetration test (CPT), (3) measurement of in-situ shear wave velocity $\left(\mathrm{V}_{\mathrm{s}}\right)$, and (4) the Becker penetration test (BPT). The oldest, and still the most widely used of these, is the SPT, and SPT-based methods will be the major focus of the following sections.

\subsubsection{SPT-Based Triggering Assessment}

The use of the SPT as a tool for the evaluation of liquefaction potential first began after the 1964 Great Alaskan Earthquake $(\mathrm{M}=8+)$ and the 1964 Niigata Earthquake $(\mathrm{M} \approx 7.5)$, both of which produced significant number of liquefactioninduced failure case histories (e.g.: Kishida 1966; Seed and Idriss 1971). As discussed by the NCEER Working Group (NCEER 1997; Youd et al. 2001), one of the most widely accepted and widely used SPT-based correlations is the "deterministic" relationship proposed by Seed, et al. (1984, 1985). Figure 19.6 shows this relationship, with minor modification at low CSR (as recommended by the NCEER Working Group; NCEER 1997). This familiar relationship is based on comparison between SPT N-values, corrected for both effective overburden stress and energy, equipment and procedural factors affecting SPT testing (to $\mathrm{N}_{1,60}$-values) vs. intensity of cyclic loading, expressed as magnitude-weighted equivalent uniform cyclic stress ratio $\left(\mathrm{CSR}_{\mathrm{eq}}\right)$. As shown in Fig. 19.6, the relationship between corrected $\mathrm{N}_{1,60}$-values and the intensity of cyclic loading required to trigger liquefaction is also a function of fines content. Although widely used in practice, this relationship is dated, and does not make use of an increasing body of field case history data from seismic events that have occurred since 1984. It is particularly lacking data from cases where peak ground shaking levels were high $(\mathrm{CSR}>0.25)$, an increasingly common design range in regions of high seismicity. This correlation also has no formal probabilistic basis, and so provides no insight regarding either uncertainty or probability of liquefaction. Efforts at development of similar, but formally probabilistically-based, correlations have been published by a number of researchers, including Liao et al. (1988, 1998), and more recently Youd and Noble (1997), and Toprak et al. (1999). Cetin (2000) reassessed available case history data with improved understanding in geotechnical and earthquake engineering practice and recommended updated probabilistically-based liquefaction boundary curves for liquefaction triggering. Figure 19.6 comparatively presents these methods (boundaries corresponding to 5, 20,50,80 and $95 \%$ probability of liquefaction) along with the "deterministic" boundaries given in the early work Seed et al. (1984). As revealed by this figure, Cetin et al. (2004) produces a more accurate and precise set of predictions.

Key elements in the development of Cetin et al. (2004) were: (1) accumulation of a significantly expanded database of field performance case histories, (2) use of 

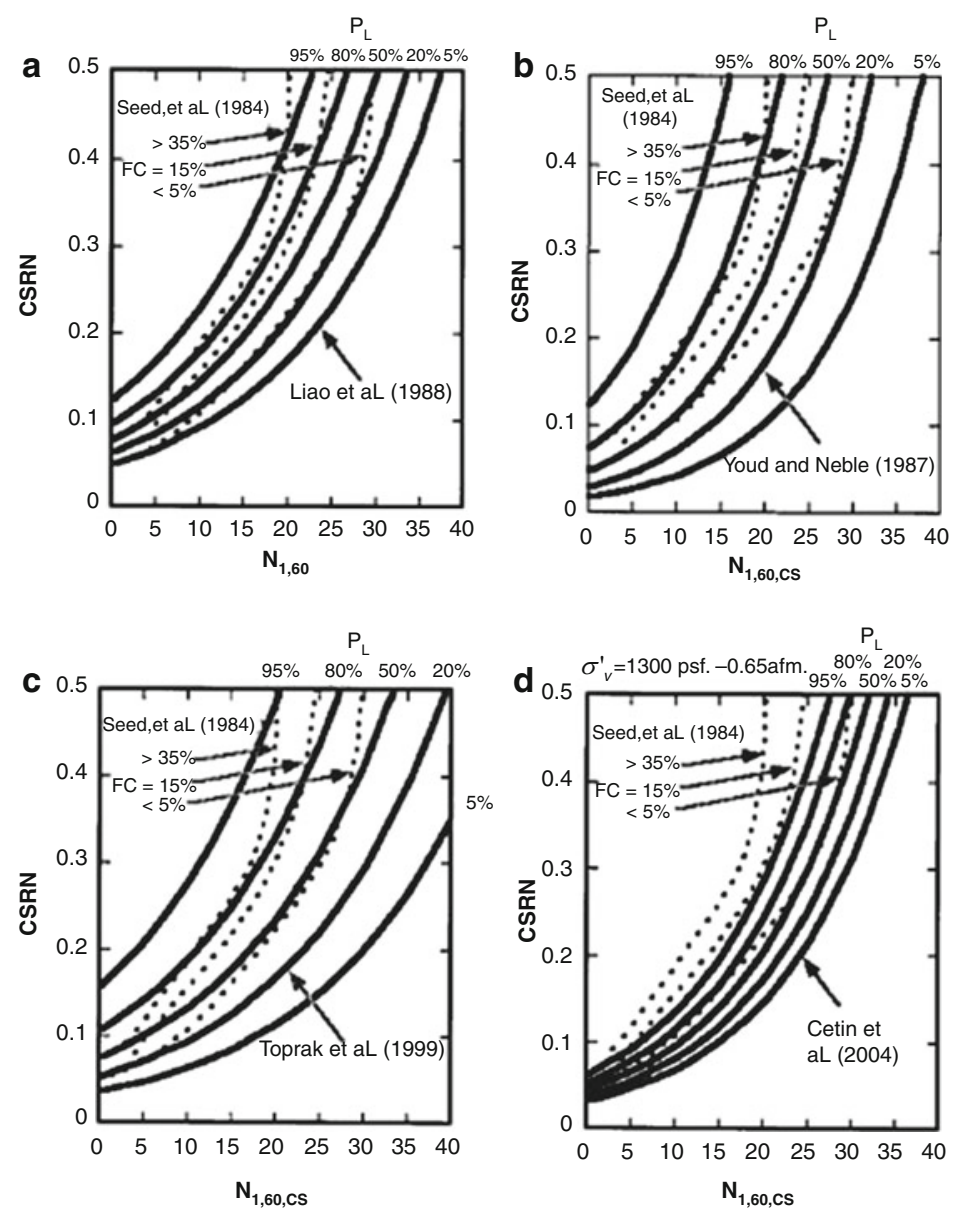

Fig. 19.6 Comparison of the existing methods for evaluation of liquefaction potential. (a) Liao et al. (1988). (b) Youd and Noble (1997). (c) Toprak et al. (1999). (d) Cetin et al. (2004)

improved knowledge and understanding of factors affecting interpretation of SPT data, (3) incorporation of improved understanding of factors affecting site-specific ground motions (including directivity effects, site-specific response, etc.), (4) use of improved methods for assessment of in-situ cyclic shear stress ratio (CSR), (5) screening of field data case histories on a quality/uncertainty basis, and (6) use of higher-order probabilistic tools (Bayesian Updating). Bayesian updating methodology (a) allowed for simultaneous use of more descriptive variables than most prior studies, and (b) allowed for appropriate treatment of various contributing sources of aleatory and epistemic uncertainty. The resulting relationships not only provide greatly reduced uncertainty, they also help to resolve a number of corollary issues that have long been difficult and controversial, including: (1) magnitudecorrelated duration weighting factors, (2) adjustments for fines content, and 
(3) corrections for effective overburden stress. Moreover, non-linear mass participation factor $\left(r_{d}\right)$, which is a significant component of the "simplified procedure" of Seed and Idriss (1971) (Eq. 19.2), was re-evaluated based on the results of 2,153 seismic site response analyses. Cetin and Seed (2002) developed a relation in terms of depth $(d)$, moment magnitude $\left(\mathrm{M}_{\mathrm{w}}\right)$, peak horizontal ground surface acceleration $\left(\mathrm{a}_{\max }\right)$ and stiffness of the site $\left(\mathrm{V}_{\mathrm{s}, 12}\right.$ in $\left.\mathrm{m} / \mathrm{s}\right)(\mathrm{Eq}$. 19.3).

$$
C S R_{d e n k}=0.65 \cdot \frac{a_{m a k s}}{g} \cdot \frac{\sigma_{v}}{\sigma_{v}^{\prime}} \cdot r_{d}
$$

For $\mathbf{d}<\mathbf{2 0 m}$

$$
r_{d}\left(d, M_{w}, a_{\max }, V_{s, 12}^{*}\right)=\frac{\left[1+\frac{-23.013-2.949 \cdot a_{\max }+0.999 \cdot M_{w}+0.0525 \cdot V_{s, 12}^{*}}{16.258+0.201 \cdot e^{0.341 \cdot\left(-d+0.0785 \cdot V_{s, 12}^{*}+7.586\right)}}\right]}{\left[1+\frac{-23.013-2.949 \cdot a_{\max }+0.999 \cdot M_{w}+0.0525 \cdot V_{s, 12}^{*}}{16.258+0.201 \cdot e^{0.341 \cdot\left(0.0785 \cdot V_{s, 12}^{*}+7.586\right)}}\right]} \pm \sigma_{\varepsilon r_{d}}
$$

For $\mathrm{d} \geq \mathbf{2 0 m}$

$$
\begin{aligned}
r_{d}\left(d, M_{w}, a_{\max }, V_{s, 12}^{*}\right)= & \frac{\left[1+\frac{-23.013-2.949 \cdot a_{\max }+0.999 \cdot M_{w}+0.0525 \cdot V_{s, 12}^{*}}{16.258+0.201 \cdot e^{0.341 \cdot\left(-20+0.0785 \cdot V_{s, 12}^{*}+7.586\right)}}\right]}{\left[1+\frac{-23.013-2.949 \cdot a_{\max }+0.999 \cdot M_{w}+0.0525 \cdot V_{s, 12}^{*}}{16.258+0.201 \cdot e^{0.341 \cdot\left(0.0785 \cdot V_{s, 12}^{*}+7.586\right)}}\right]} \\
& -0.0046 \cdot(d-20) \pm \sigma_{\varepsilon r_{d}}
\end{aligned}
$$

$$
\begin{aligned}
& \text { For } \mathbf{d}<\mathbf{1 2} \mathbf{~ m ~} \sigma_{\varepsilon r_{d}}(d)=d^{0.850} \cdot 0.0198 \\
& \text { For } \mathbf{d} \geq \mathbf{1 2} \mathbf{~ m ~} \sigma_{\varepsilon r_{d}}(d)=12^{0.850} \cdot 0.0198
\end{aligned}
$$

The close form solution of Cetin et al. (2004) for the assessment of the probability of liquefaction, which involves the corrections for the influence of fines content, duration and effective stress, is given in Eq. (19.4).

$P_{L}\left(N_{1,60}, C S R, M_{w}, \sigma_{v}^{\prime}, F C\right)=\Phi\left(-\frac{\left(\begin{array}{l}N_{1,60} \cdot(1+0.004 \cdot F C)-13.32 \cdot \ln (C S R) \\ -29.53 \cdot \ln \left(M_{w}\right)-3.70 \cdot \ln \left(\sigma_{v}^{\prime} / P_{a}\right) \\ +0.05 \cdot F C+16.85\end{array}\right)}{2.70}\right)$ 
where $\mathrm{P}_{\mathrm{L}}=$ probability of liquefaction in decimals (i.e. $\mathrm{PL}=50 \%$ is represented as $0.30)$; $\mathrm{CSR}_{\mathrm{eq}}$ is not "adjusted" for magnitude (duration), overburden or fines effects (i.e.: corrections are executed within the equation itself); $\mathrm{FC}=$ percent fine content (by dry weight) expressed as an integer (e.g., $12 \%$ fine is expressed as $\mathrm{FC}=12$ ) with the limit of $5 \leq \mathrm{FC} \leq 35 ; \mathrm{Pa}=$ atmospheric pressure $(=1 \mathrm{~atm} \sim 100 \mathrm{kPa} \sim 2,000$ psf) in the same units as the in situ vertical effective stress; and $\Phi$ standard cumulative normal distribution. Also the cyclic resistance ratio for a given probability of liquefaction can be expressed as follows:

$C R R\left(N_{1,60}, M_{w}, \sigma_{v}^{\prime}, F C, P_{L}\right)=\exp \left[\frac{\left(\begin{array}{c}N_{1,60} \cdot(1+0.004 \cdot F C)-29.53 \cdot \ln \left(M_{w}\right) \\ -3.70 \cdot \ln \left(\sigma_{v}^{\prime} / P_{a}\right)+0.05 \cdot F C+ \\ 16.85+2.70 \cdot \Phi^{-1}\left(P_{L}\right)\end{array}\right)}{13.32}\right]$

where $\Phi^{-1}\left(P_{L}\right)=$ inverse of the standard cumulative normal distribution (i.e., mean $=0$, and standard deviation $=1$ ). For spreadsheet construction purposes, the command in Microsoft Excel for this specific function is "NORMINV $\left(P_{L}, 0,1\right)$ ".

If a user prefers using this method to calculate factor of safety (i.e. for deterministic analysis), then CRR corresponding to $\mathrm{P}_{\mathrm{L}}=50 \%$ (0.5) should be used as the capacity term. Note that a factor of safety in the range of $1.0-1.20$ is typically used.

More recently, Idriss and Boulanger (2006) proposed a new semi-empirical approach for the evaluation of liquefaction triggering. The similarity of the proposed boundary curves with the ones proposed by Seed et al. (1985) is remarkable and should be noted. The presence of a number of alternative liquefaction triggering methodologies is a source of confusion for practicing engineers, and indicates the lack of consensus among researchers. For the purpose of clarifying the sources of this disagreement, integral components of liquefaction triggering assessments will be revisited, and the degree of consensus in these components will be discussed. For this purpose four sets of comparison charts were prepared. As shown in Fig. 19.7, the disagreement in the recommended $r_{d}$ values is remarkable, and depending on the adopted $r_{d}$ model, CSR values can be different by a factor of 1.1-1.2 at shallow depths. Similarly, the scatter in magnitude scaling (or duration weighting) factors, especially at smaller magnitude events is large and may produce CSR estimates different by a factor of $1.5-3 . \mathrm{K}_{\sigma}$ correction is another source of controversy and deserves further discussion. In 1984, Seed et al. presented their widely used relationship between procedure and overburden-corrected SPT blow counts, $\mathrm{N}_{1,60}$ and CSR triggering liquefaction during a $\mathrm{M}_{\mathrm{w}}=7.5$ event. Consistent with Seed (1983) and Seed et al. (1984), with the argument that $\mathrm{K}_{\sigma}$ corrections were not applied when assessing liquefaction triggering case histories (i.e.: back analysis), which establish the basis of liquefaction triggering relationship, consistently, it was recommended not to apply $K_{\sigma}$ corrections for liquefaction engineering assessment 

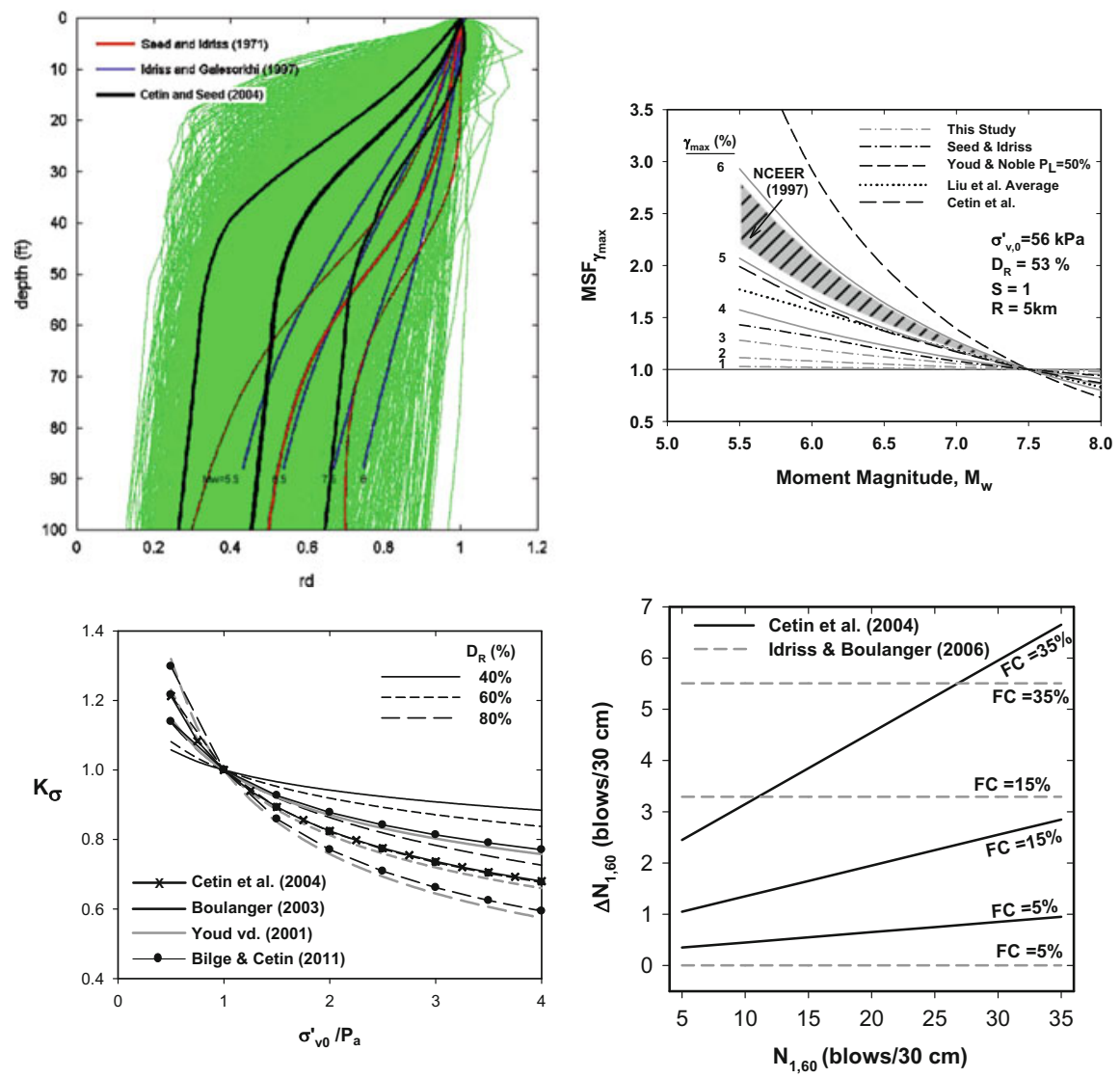

Fig. 19.7 Comparison of the existing methods for the evaluation of $r_{d}$, MSF, Ko and fines corrections

of soil layers (i.e.: forward analysis) with a vertical effective stress less than 1 atm. Unfortunately, this -at first glance consistent and practical choice- produced unconservatively biased predictions for deep soil layers due to the fact that median vertical effective stress of liquefaction triggering case histories is $56 \mathrm{kPa}$ (or $65 \mathrm{kPa}$ if weighting applied, Cetin 2000) but not $100 \mathrm{kPa}$. Last but not least, due to asymptotic nature of triggering curves, fines corrections applied on $\mathrm{N}_{1,60}$ can be extremely critical. In the literature, there exist contradicting arguments about if and how fines affect cyclic straining, pore pressure and stiffness degradation response of granular soils.

It is quite natural that the scattered correction factors produce a wide range of liquefaction triggering curves. However, it should be noted that practicing engineers may eliminate some of the uncertainty in liquefaction triggering predictions by consistently following the correction scheme of the original reference, since these corrections were consistently applied in the processing of case histories as well. Unfortunately, even consistency does not always guarantee the elimination of 
bias, if these models are used to predict the liquefaction performance of a site subjected to an earthquake shaking, which are different from "typical" (i.e.: median values) of the case history databases.

Within the confines of this chapter, due to page limitations and their wide use, only SPT-based methods were discussed. Regarding the CPT-based methods, readers are referred to the deterministic and probabilistic methods of Robertson and Wride (1998) and Moss et al. (2006), respectively. Shear wave velocity and Becker penetration test-based methods are relatively less frequently used; but readers are referred to Kayen et al. (2013) and Harder and Seed (1986), respectively, for a complete review of available literature.

It should be noted that all these methods are applicable to either clean sands or sands with limited amount of fines. As discussed earlier, silt and clay mixtures may also be susceptible to cyclic loading-induced strength loss and deformations. Unfortunately, research interest on their cyclic response picked up only recently, and hence, a comprehensive effort summarizing their cyclic performance is still missing. Yet, Boulanger and Idriss (2007) needs to be referred to as a practical tool, which is waiting to be tested via sufficient number of case histories.

Following sections are devoted to the discussion of seismic strength and deformation responses of soils, which allows a direct evaluation of seismic soil performance.

\subsection{Assessment of Seismic Strength Response of Soils}

There is a significant tendency towards the performance-based approaches in today's engineering profession. From seismic soil response point of view, this tendency puts forward the prediction of strength and deformation performances. Actually, they establish the basis of second and third level liquefaction engineering assessments, as outlined by Seed et al. (2001) (Fig. 19.1). For the sake of consistency, cyclic strength loss will be discussed before the discussion of cyclic straining.

\subsubsection{Seismic Strength Performance of Clean Sands and Silt - Sand Mixtures}

Most of the previous efforts have focused on saturated clean sands and non-plastic silt - sand mixtures. Shear strength of these soils solely rely on the effective stress state and inter granular friction. Thus, an increase in seismically-induced excess pore water pressure may cause a significant reduction in shear strength (most extreme case is liquefaction) of saturated cohesionless soils.

Consistent with liquefaction triggering methodologies, there exist two alternatives: (i) sampling and laboratory testing, and (ii) correlation of post-liquefaction strength with field case history data. The "steady-state" approach (e.g.: Poulos 
Fig. 19.8 Recommended relationship between $\mathrm{s}_{\mathrm{u}, \mathrm{r}}$ and $\mathrm{N}_{1,60, \mathrm{CS}}$ (After Seed and Harder 1990)

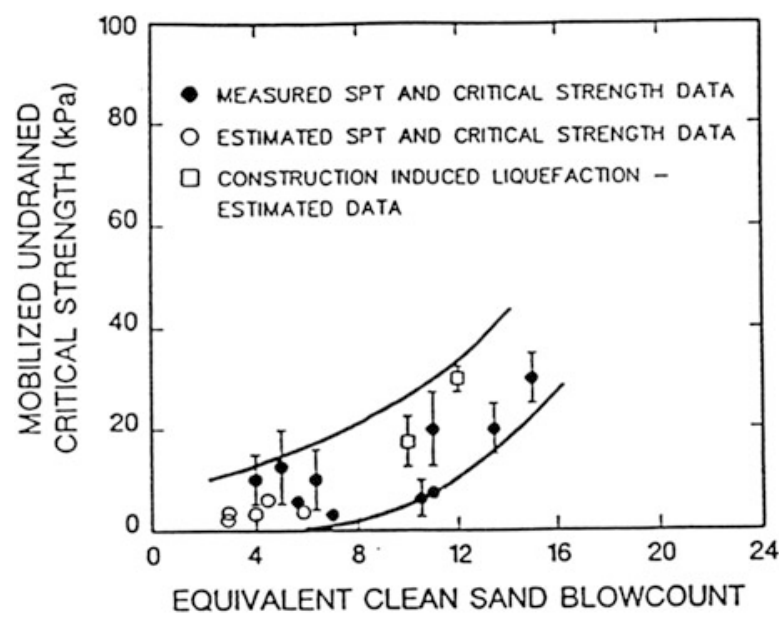

et al. 1985), has benefitted from laboratory testing of both reconstituted and high-quality "undisturbed" samples, and a systematic basis for correction has been proposed for post-liquefaction "steady-state" strengths due to inevitable disturbance and densification effects that occurred during sampling and re-consolidation phases of undrained shearing. The method was eventually claimed to produce post-liquefaction strengths that were much higher than those backcalculated from field failure case histories (e.g. Seed et al. 1989). Hence, most research has diverted to the latter approach.

After the pioneering work of Seed (1987), many researchers (e.g., Davis et al. 1988; Seed and Harder 1990; Robertson et al. 1992; Stark and Mesri 1992; Ishihara 1993; Wride et al. 1999) have performed extensive research to assess postliquefaction shear strength of saturated sandy soils. Among these, Seed and Harder (1990) along with Stark and Mesri (1992) were widely accepted and used. Seed and Harder (1990) defined residual shear strength $\left(\mathrm{s}_{\mathrm{u}, \mathrm{r}}\right)$ in terms of procedure-, energy-, overburden stress- and fines- corrected SPT blow counts $\left(\mathrm{N}_{1,60, \mathrm{CS}}\right)$ as presented in Fig. 19.8. Alternatively, Stark and Mesri (1992) normalized residual shear strength by initial vertical effective stress, and presented a chart solution as a function of $\mathrm{N}_{1,60, \text { CS }}$ as shown in Fig. 19.9.

Recently, Olson and Stark (2002) revisited the available case history database and recommended the post-liquefaction shear strength relationships as a function of SPT blow counts and CPT tip resistance, as given in Eqs. (19.6) and (19.7), respectively.

$$
\text { For } N_{1,60} \leq 12, \quad \frac{s_{u, S}}{\sigma_{v 0}^{\prime}}=0.03+0.0075\left[\left(N_{1}\right)_{60}\right] \pm 0.03
$$




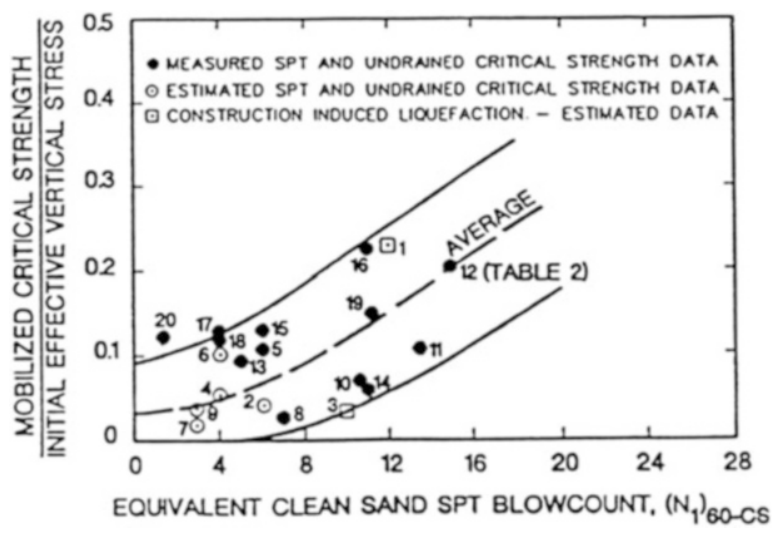

Fig. 19.9 Recommended relationship between $s_{u, r} / \sigma_{v, 0}^{\prime}$ and $N_{1,60, C S}$ (After Stark and Mesri 1992)

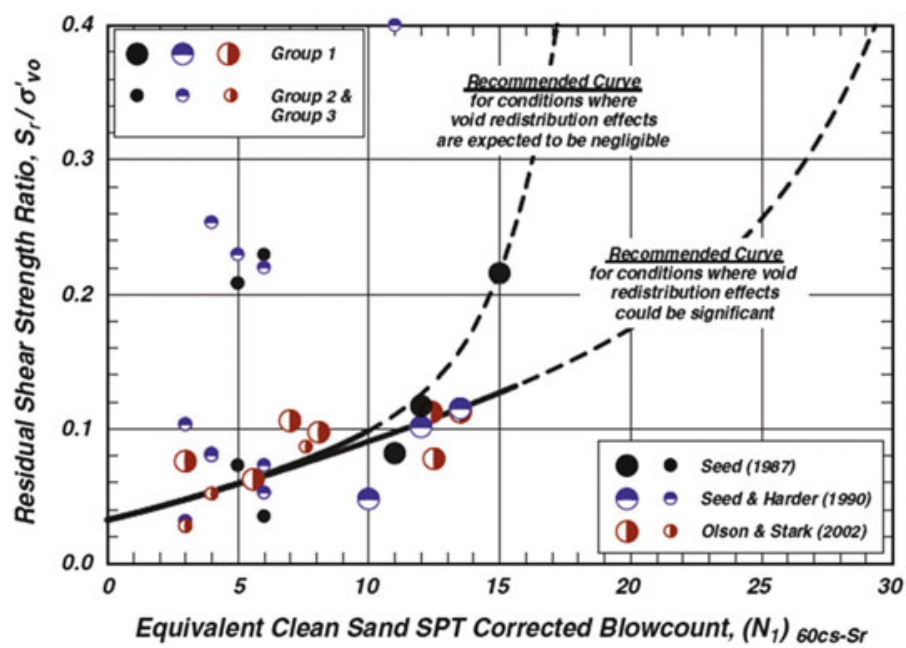

Fig. 19.10 Residual shear strength ratio, $S_{\mathrm{r}} / \sigma_{\mathrm{v}, 0}^{\prime}$, of liquefied soil versus equivalent clean-sand, SPT corrected blow count for $/ \sigma_{\mathrm{v}, 0}^{\prime}$ less than $400 \mathrm{kPa}$ (After Idriss and Boulanger 2007)

$$
\text { For } q_{c 1} \leq 6.5 M P a, \frac{s_{u, S}}{\sigma_{v 0}^{\prime}}=0.03+0.0143\left(q_{c 1}\right) \pm 0.03
$$

More recently, Idriss and Boulanger (2007) re-assessed earlier efforts and existing case histories, and recommended two sets of solutions again for SPT and CPT data as presented in Figs. 19.10 and 19.11, respectively. Moreover, authors also developed the following close form solutions for the estimation of residual shear strength by taking into account void redistribution effects. If the influence of void redistribution is significant, residual shear can be estimated as follows: 


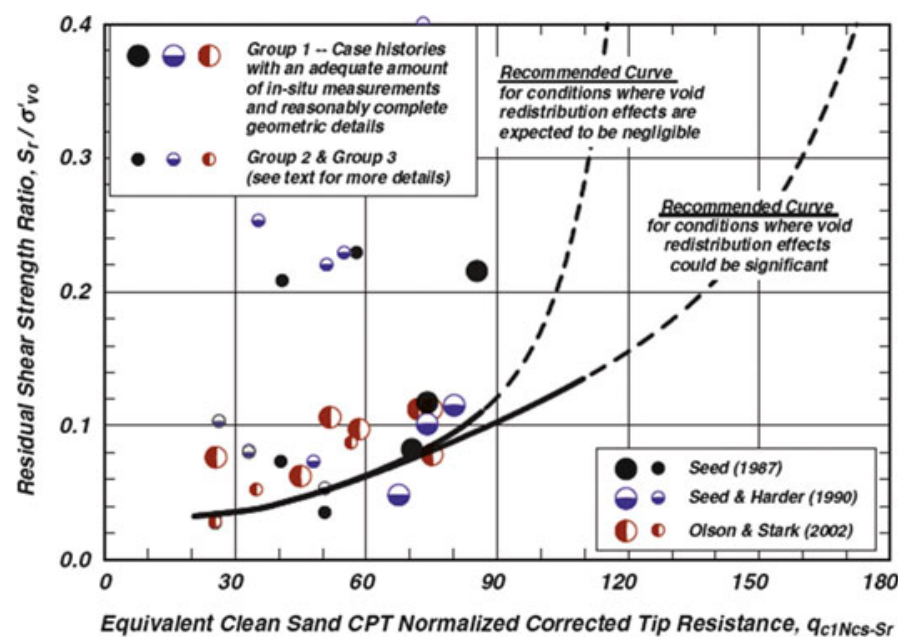

Fig. 19.11 Residual shear strength ratio, $\mathrm{S}_{\mathrm{r}} / \sigma_{\mathrm{v}, 0}^{\prime}$, of liquefied soil versus CPT-qc1Ncs-Sr values for for $/ \sigma^{\prime}, 0$ less than $400 \mathrm{kPa}$ (After Idriss and Boulanger 2007)

$$
\begin{aligned}
& \frac{S_{u, r}}{\sigma_{v 0}^{\prime}}=\exp \left(\frac{N_{1,60, C S}}{16}+\left(\frac{N_{1,60, C S}-16}{21.2}\right)^{3}-3.0\right) \leq \tan \phi^{\prime} \\
& \frac{S_{u, r}}{\sigma_{v 0}^{\prime}}=\exp \left(\frac{q_{c, 1 N, C S}}{24.5}-\left(\frac{q_{c, 1 N, C S}}{61.7}\right)^{2}+\left(\frac{q_{c, 1 N, C S}}{106}\right)^{3}-4.42\right) \leq \tan \phi^{\prime}
\end{aligned}
$$

Alternatively, if void redistribution effects are negligible,

$$
\begin{aligned}
\frac{S_{u, r}}{\sigma_{v 0}^{\prime}}= & \exp \left(\frac{q_{c, 1 N, C S}}{24.5}-\left(\frac{q_{c, 1 N, C S}}{61.7}\right)^{2}+\left(\frac{q_{c, 1 N, C S}}{106}\right)^{3}-4.42\right) \\
& \times\left(1+\exp \left(\frac{q_{c, 1 N, C S}}{11.1}-9.82\right)\right) \leq \tan \phi^{\prime} \\
\frac{S_{u, r}}{\sigma_{v 0}^{\prime}}= & \exp \left(\frac{N_{1,60, C S}}{16}+\left(\frac{N_{1,60, C S}-16}{21.2}\right)^{3}-3.0\right) \\
& \times\left(1+\exp \left(\frac{N_{1,60, C S}}{2.4}-6.6\right)\right) \leq \tan \phi^{\prime}
\end{aligned}
$$

where $\phi^{\prime}$ represents the effective stress based internal angle of friction 
Fig. 19.12 Cyclic shear strain induced reduction in shear strength (After Castro and Christian 1976)

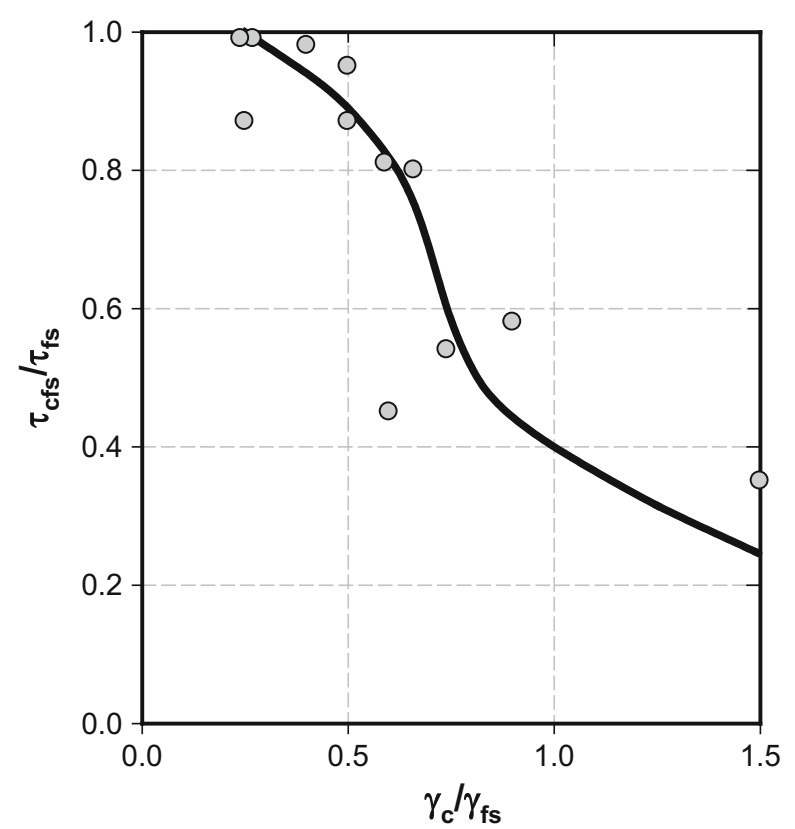

The recent effort of Idriss and Boulanger (2007) is considered to be an improvement over previous studies due to increased number of case history data points as well as consideration of the void redistribution effects. However, considering the scatter in case history data, the recommendation of a deterministic boundary curve (instead of upper and lower bounds or probabilistically based boundaries) is judged to be the limitation of the study.

\subsubsection{Seismic Strength Performance of Silt-Clay Mixtures}

Although post-cyclic strength loss is accepted to be more critical for saturated cohesionless soils, it could also be a serious threat for cohesive soils depending on intensity and duration of shaking and their undrained shear strength. Depending on the dilatancy properties of soil, the intensity of shaking and also post-cyclic stress path, post-cyclic shear strength may be significantly different than monotonic shear strength. Additionally, shear strength of most clays decreases due to remolding and excess pore pressure increase during cyclic loading.

In their pioneer study, Thiers and Seed (1969) proposed a chart solution given in Fig. 19.12, where the ratio of post-cyclic to monotonic shear strength was defined as a function of cyclic shear strain amplitude to shear strain at which monotonic failure takes place. Figure 19.12 reveals that strength loss may be a factor of five. However, as long as the amplitude of the cyclic shear strain $\left(\gamma_{c}\right)$ is less than half of the strain level required for monotonic failure $\left(\gamma_{f s}\right)$, the reduction in shear strength is less than 
$10 \%$. Later, Lee and Focht (1976), Koutsoftas (1978) and Sherif et al. (1977) provided experimental data supporting the findings of Thiers and Seed (1969). Additionally, Sangrey and France (1980) presented a supporting theoretical framework on the basis of critical state soil mechanics.

Castro and Christian (1976) also investigated post-cyclic shear strength of various types of soils. They addressed that $s_{u, p c}$ predictions using effective stress based Mohr Coulomb failure criterion might be misleading since this approach ignored the possible dilative nature of soil specimens. They have also stated that post-cyclic shear strength $\left(s_{u, p c}\right)$ of clayey soils were very similar to their monotonic shear strength $\left(s_{u}\right)$. The latter observation is based on the results of 4 cyclic tests performed on clayey soils having PI and LI values varying between 15-19 and $0.27-0.69$, respectively. Thus, it is believed that the findings of the authors may not be valid for potentially liquefiable fine grained soils, and their statement on the similarity $s_{u, p c}$ and $s_{u}$ values is, least to say, unconservative.

Van Eekelen and Potts (1978) proposed the following expression relating $s_{u, p c}$ and $s_{u}$ of clayey soils.

$$
\frac{s_{u, p c}}{s_{u}}=\left(1-r_{u}\right)^{\chi / \lambda}
$$

where $\chi$ and $\lambda$ are the critical state swell and compression coefficients, respectively, and the determination of them requires oedometer testing. Using consolidation theory as a theoretical basis, Yasuhara (1994) proposed a framework for estimating post-cyclic shear strength of cohesive soils considering both undrained and drained loading conditions. According to Yasuhara's observations the extent of the decrease in shear strength varies from 10 to $50 \%$ of monotonic shear strength. Yasuhara (1994) proposed the close form solution presented in Eq. (19.11).

$$
\frac{s_{u, c y}}{s_{u, N C}}=(O C R)_{q} \cdot\left(\frac{\Lambda_{0}}{1-C_{s} / C_{c}}-1\right)
$$

where $s_{u, c y}$ and $s_{u, N C}$ are post-cyclic and monotonic shear strengths, respectively; $C_{s}$ and $C_{c}$ are swelling and compressibility indices, respectively; $(O C R)_{q}$ is the ratio of mean effective stresses before $\left(p_{i}^{\prime}\right)$ and after $\left(p_{e}^{\prime}\right)$ the application of cyclic shear stresses; and $\Lambda_{0}$ is a material constant determination of which requires additional consolidation testing. Based on the findings of Ue et al. (1991), Yasuhara proposed the following equation for the prediction of $\Lambda_{0} /\left(1-C_{s} / C_{c}\right)$ term;

$$
\Lambda_{0} /\left(1-C_{s} / C_{c}\right)=0.939-0.002 \cdot P I
$$

While this framework is arguably the most complete approach to assess postcyclic shear strength of cohesive soils, it is judged to suffer from the following limitations: (i) applicability to post-liquefaction residual shear strength problems is still arguable, (ii) in the verification set, Yasuhara used clayey soils with high PI values reaching up to 320 and naturally none of the specimens experienced high $r_{u}$ 
Fig. 19.13 Database used for development of Eq. (19.12)

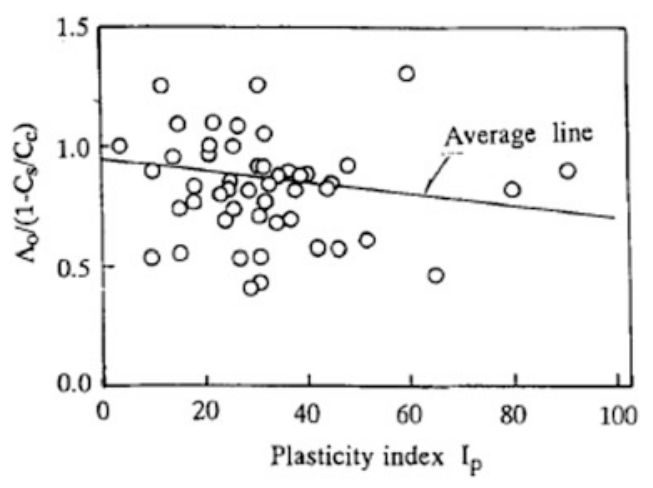

levels. (iii) there is no information on moisture content, so it is not possible to comment on liquefaction susceptibility of tested specimens. $(O C R)_{q}$ is another important component of this model; yet its estimation is not trivial. This term has been used by various researchers previously: Okamura (1971) referred to it as "disturbance ratio", Matsui et al. (1980) used the term "equivalent overconsolidation ratio" and Yasuhara et al. (1983) called it as "apparent" or "quasioverconsolidation ratio". According to Yasuhara, its value depends on cyclically induced excess pore water pressure ratio. Following simplified expression was proposed for Yasuhara (1994) to predict $(O C R)_{q}$.

$$
(O C R)_{q}=(O C R)^{1-C_{s} / C_{c}}
$$

where $O C R$ is the overconsolidation ratio of the tested specimen. For the sake of producing a practical approach, Yasuhara once again adopted a relation given by Ue et al. (1991) for prediction of $C_{s} / C_{c}$ which is given as follows:

$$
C_{s} / C_{c}=0.185+0.002 \cdot P I
$$

Expressing the parameters as a function of PI is a very practical approach; yet in turn, the success of Yasuhara's method strongly depends on Ue et al. (1991)'s correlations. Performance of these correlations is waiting to be tested since database of Ue et al. involves significant amount of data scatter as presented by Figs. 19.13 and 19.14 for Eqs. 19.12 and 19.14, respectively. Hence practicing engineers need to use it with caution due to the large uncertainty involved.

Although almost four decades have passed since the pioneer efforts on the evaluation of post-cyclic strength of silt and clay mixtures, current state of literature reveals that more needs to be done. This discussion revealed that these early efforts did not specifically focus on cyclic response of soils with significant straining and excess pore pressure generation potential. In these extremes, specimens may lose significant fraction of their initial shear strength. Inspired from this gap, a probabilistic-based semi-empirical model (Eq. 19.14) is developed to predict the ratio of the minimum shear strength during the course of cyclic loading to initial 
Fig. 19.14 Database used for development of Eq. (19.14)

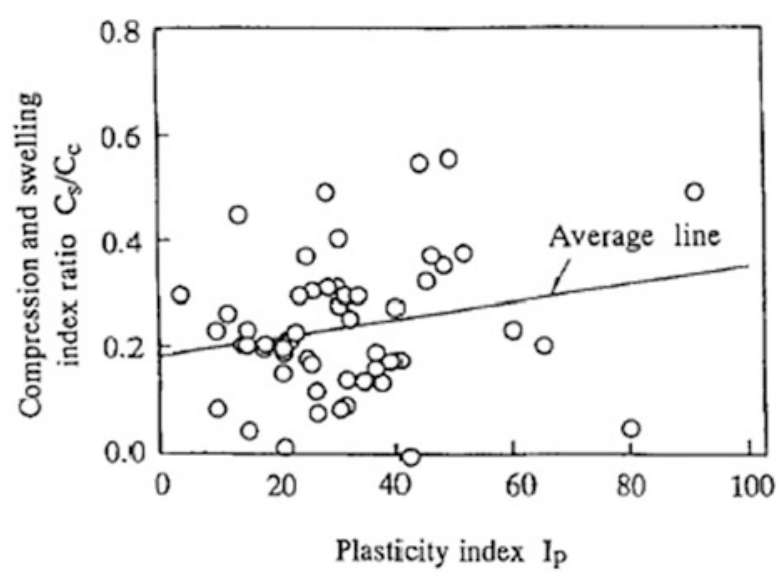

Fig. 19.15 Variation of strength ratio $\left(\mathrm{s}_{\mathrm{u}, \mathrm{iq}} / \mathrm{s}_{\mathrm{u}, \mathrm{st}}\right)$ as a function of LI and PI

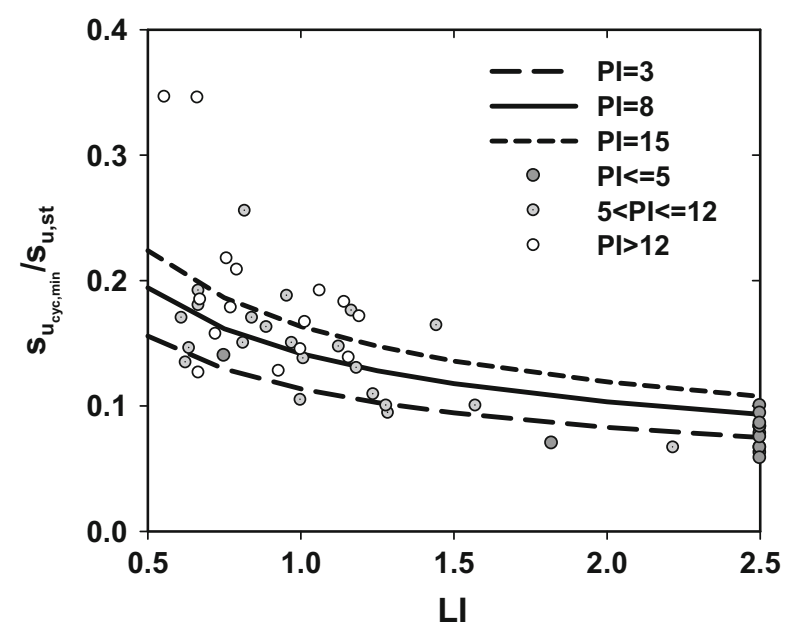

undrained shear strength as a function of Atterberg limits (PI and liquidity index, LI). Moreover, Fig. 19.15 presents the proposed model schematically. Readers are referred to Bilge (2010) for further details of model development.

$$
\ln \left(\frac{s_{u_{c y c} \text { min }}}{s_{u, s t}}\right)=\ln \left(0.089 \cdot P I^{0.226} \cdot L I^{-0.455}\right) \pm 0.213
$$

It should be noted that the proposed model is developed for the estimation of shear strength reduction due to cyclic-induced remolding and increase in excess pore pressure. 


\subsection{Assessment of Seismic Deformation Response of Soils}

Despite major advances in soil liquefaction engineering, assessment of anticipated post-cyclic strain and deformations has remained a very "soft" area of practice. Within the confines of this chapter existing methods for assessment of cyclicinduced deformations will be discussed.

\subsubsection{Seismic Deformation Response of Clean Sands and Silt - Sand Mixtures}

Numerous researchers have tried to quantify cyclic (or sometimes liquefactioninduced) soil straining through use of deterministic techniques based on laboratory test results and/or correlations of in-situ "index" tests with observed field performance data. Seed and Idriss (1971) proposed "simplified procedure", a widely accepted and used methodology, where cyclic stress ratio (CSR), and overburden, fines- and the procedure-corrected Standard Penetration Test (SPT) blow-counts $\left(N_{1,60, C S}\right)$ were selected as the load and capacity terms, respectively, for the assessment of seismic soil liquefaction triggering. Using $N_{1,60, C S}$ and CSR terms, Tokimatsu and Seed (1984) recommended a set of chart solutions for the estimation of limiting shear and post-cyclic volumetric strains based on the results of cyclic triaxial and simple shear tests performed on clean sands, further calibrated with case history performance data. Similarly, based on the results of cyclic simple shear tests, Ishihara and Yoshimine (1992) proposed cyclically-induced maximum shear and post-cyclic volumetric strain correlations, where normalized demand term was chosen as factor of safety against liquefaction, and capacity term was defined as relative density $\left(D_{R}\right)$, or cone tip resistance $\left(q_{c}\right)$, or SPT blow count $\left(N_{1,72}\right)$. Based on the results of cyclic torsional shear tests, Shamoto et al. (1998) recommended a semi-empirical constitutive model, as well as chart solutions, for the estimation of post-cyclic residual shear and volumetric strains. Recently, Wu et al. (2003) proposed cyclically-induced limiting shear and post-cyclic volumetric strain correlations based on the results of cyclic simple shear tests. Wu and Seed (2004) attempted to validate this volumetric strain relationship with ground settlement field case history data compiled from a number of earthquakes. Recommendations of all these four methods in the form of equi-shear or equi-volumetric strain contours are shown in Figs. 19.16, 19.17 and 19.18. However, direct comparisons are difficult and not fair due to different definitions of demand and capacity, as well as shear strain terms adopted.

All these deterministic methods have been regarded as the best of their kinds, and used in practical applications for many years. However, none of them considers the uncertainties associated with the nature of the problem. Recently, Cetin et al. (2009a) has introduced a new probabilistic-based framework based on the results of a comprehensive cyclic testing program. Semi-empirical models were 
Fig. 19.16 Available methods for the estimation of cyclically-induced deviatoric strains

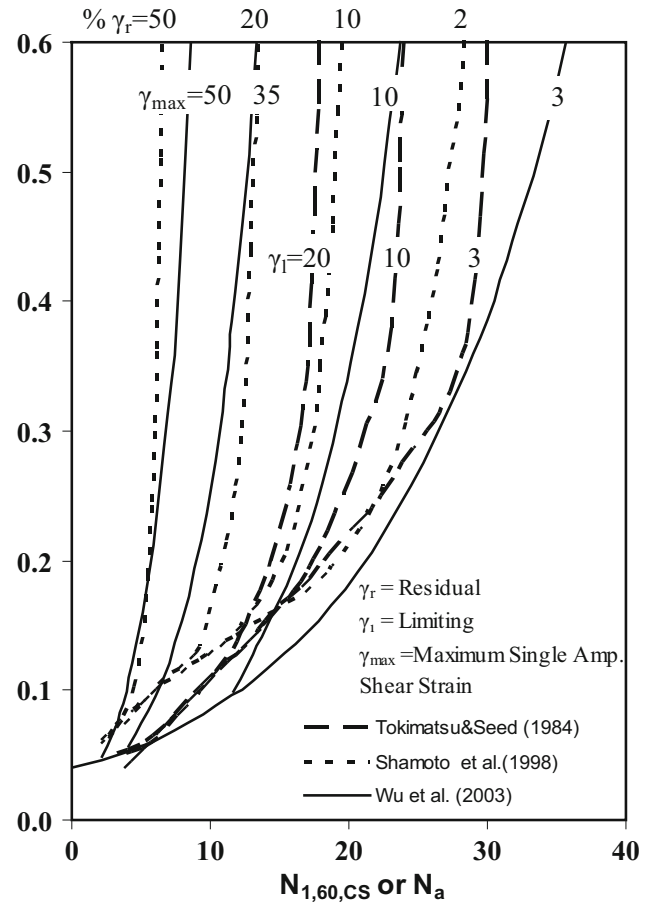

developed for estimation of maximum cyclic shear and post-cyclic reconsolidation volumetric strain potentials of saturated clean sands, as presented by Eqs. (19.16) and (19.17), respectively. Moreover, these models are presented schematically in Figs. 19.19 and 19.20, respectively.

$\ln \left(\gamma_{\max }\right)=\ln \left[\frac{-0.025 \cdot N_{1,60, C S}+\ln \left(C S R_{S S, 20,1-D, 1 \mathrm{~atm}}\right)+2.613}{0.004 \cdot N_{1,60, C S}+0.001}\right] \pm 1.880$

limit : $5 \leq N_{1,60, C S} \leq 40,0.05 \leq C S R_{S S, 20,1-D, 1 \text { atm }} \leq 0.60$ and $0 \% \leq \gamma_{\max } \leq 50 \%$

$$
\begin{aligned}
\ln \left(\varepsilon_{v}\right)= & \ln \left[1.879 \cdot \ln \left[\frac{780.416 \cdot \ln \left(C S R_{S S, 20,1-D, 1 \text { atm }}\right)-N_{1,60, C S}+2442.465}{636.613 \cdot N_{1,60, C S}+306.732}\right]\right. \\
& +5.583] \pm 0.689
\end{aligned}
$$

limit : $5 \leq N_{1,60, C S} \leq 40,0.05 \leq C S R_{S S, 20,1-D, 1 \text { atm }} \leq 0.60$ and $0 \% \leq \varepsilon_{v} \leq 5 \%$ 
Fig. 19.17 Available methods for the estimation of post-cyclic volumetric strains

Fig. 19.18 Ishihara and Yoshimine (1992) method for determining the maximum shear and postcyclic volumetric strains as a function of factor of safety against liquefaction
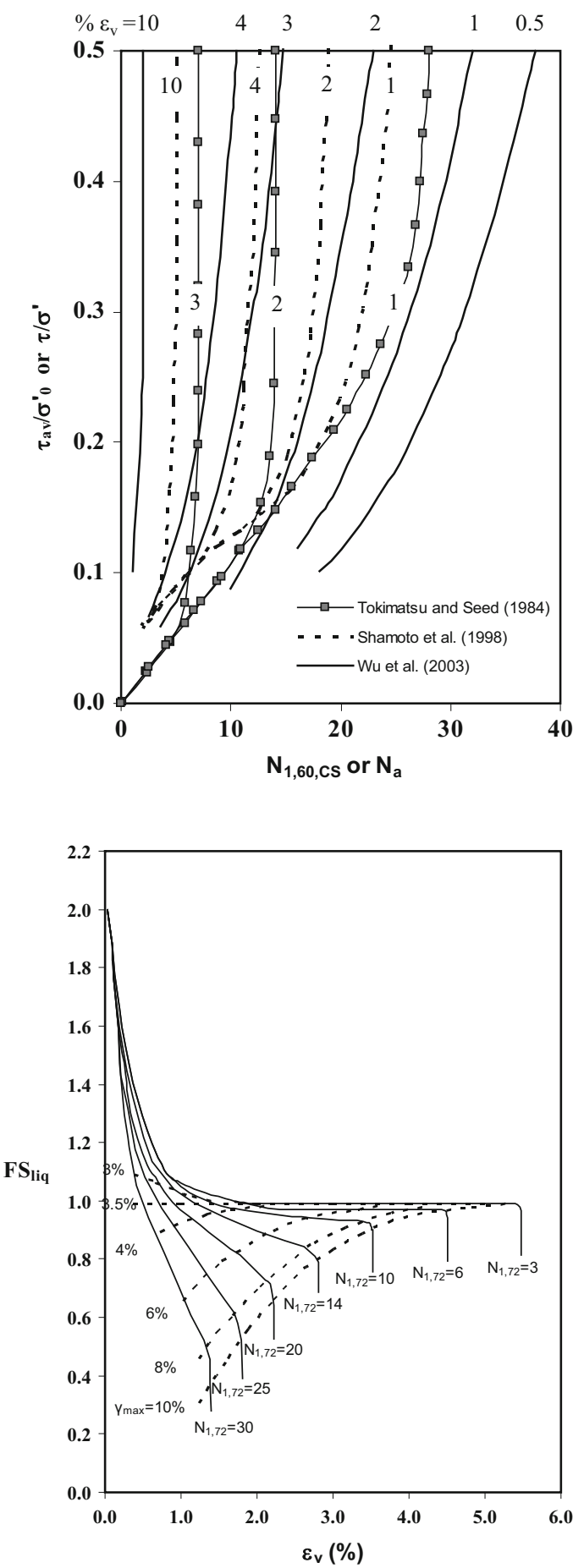
Fig. 19.19 Recommended maximum double amplitude shear strain boundary curves by Cetin et al. (2009a)

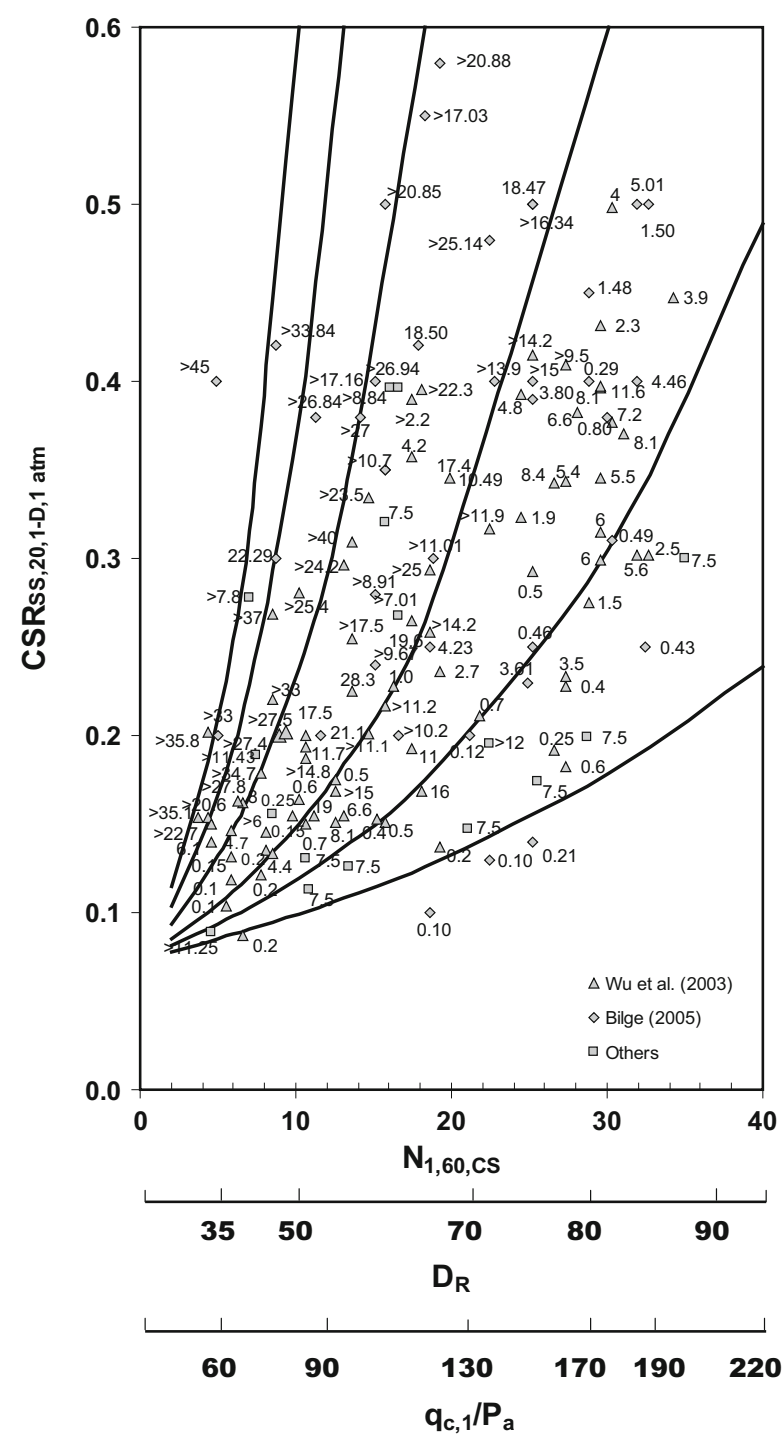

Proposed models were given in terms of $N_{1,60, C S}$ and $C S R_{S S, 20,1-D, 1 \mathrm{~atm}}$ which is the $C S R$ value corresponding to 1 dimensional, 20 uniform loading cycles simple shear test under a confining pressure of $100 \mathrm{kPa}(=1 \mathrm{~atm})$. Correction factors adopted to convert the $C S R_{\text {field }}$ value to equivalent $C S R_{S S, 20,1-D, 1 \text { atm }}$ are presented in Eq. (19.18).

$$
C S R_{S S, 20,1-D, 1 a t m}=\frac{C S R_{\text {field }}}{K_{m d} \cdot K_{M_{W}} \cdot K_{\sigma}}
$$


Fig. 19.20 Recommended post-cyclic volumetric strain boundary curves by Cetin et al. (2009a)

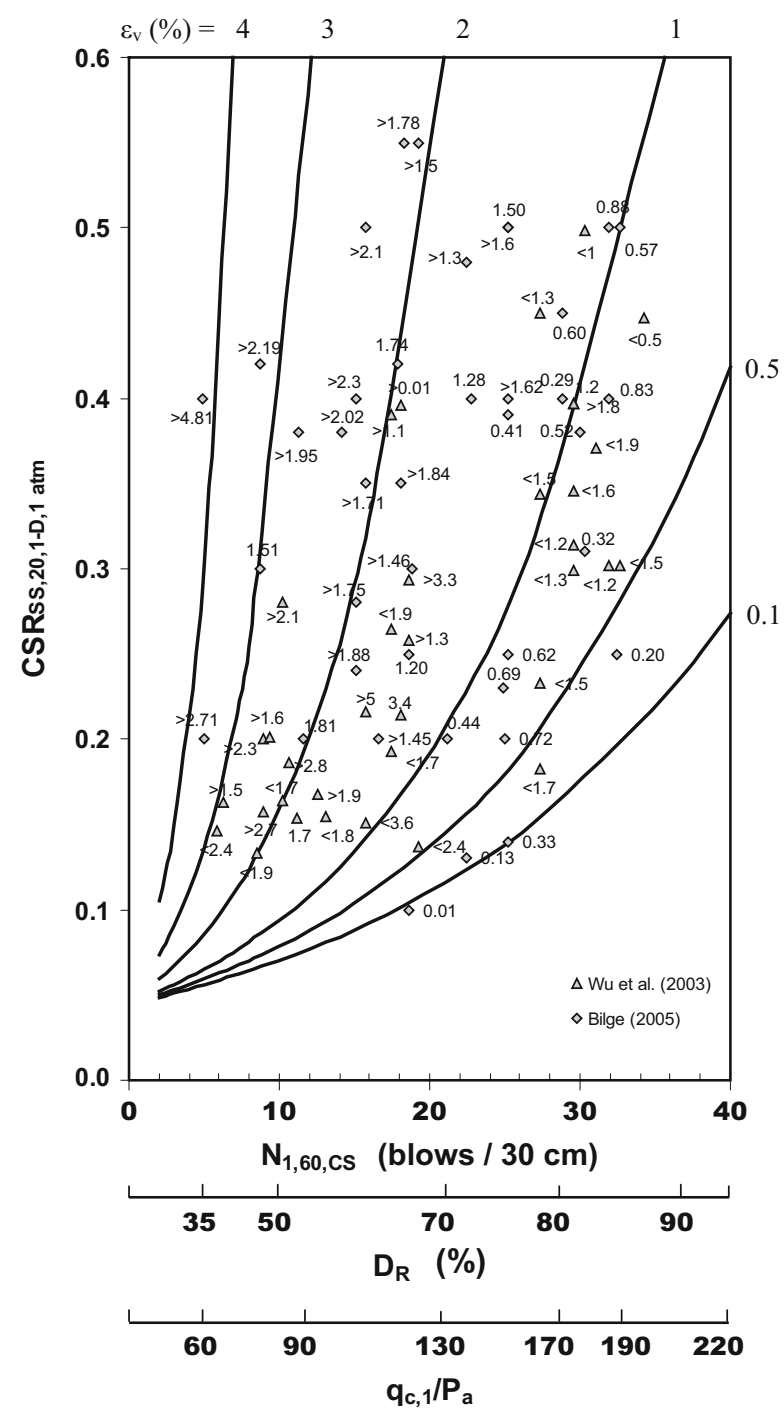

where $K_{m d}$-correction is used to convert multi-directionally applied $C S R_{\text {field }}$ value to the value of a uni-directionally applied laboratory CSR (Eq. 19.19), $K_{M w}$ -correction is used to take into account duration (magnitude) effects (Eq. 19.20) and $K_{\sigma}$ is the correction factor for varying confining effective stress conditions (Eq. 19.21).

$$
K_{m d}=0.361 \cdot \ln \left(D_{R}\right)-0.579
$$




$$
\begin{gathered}
K_{M_{W}}=\frac{87.1}{M_{w}^{2.217}} \\
K_{\sigma}=\left(\frac{\sigma_{v, 0}^{\prime}}{P_{a}}\right)^{f-1} \text { and } f=1-0.005 \cdot D_{R}
\end{gathered}
$$

The next step following the assessment of cyclic straining potential is prediction of soil deformations. In general, post-cyclic reconsolidation (volumetric) strains due to dissipation of excess pore water pressures are associated with settlements, whereas, cyclic shear strains are associated with lateral spreads. Following discussion will be devoted to the prediction of settlements and lateral spreads.

\subsubsection{Assessment of Post-cyclic Settlements}

Currently available approaches for predicting the magnitude of post-cyclic reconsolidation settlements are categorized as: (i) numerical analyses in the form of finite element and/or finite difference techniques (e.g., Martin et al. (1975), Seed et al. (1976), Booker et al. (1976), Finn et al. (1977), Liyanathirana and Poulos (2002)), and (ii) semi-empirical models developed based on laboratory, field test and performance data (e.g. Lee and Albeisa (1974), Tokimatsu and Seed (1984), Ishihara and Yoshimine (1992), Shamoto et al. (1998), Zhang et al. (2002), Wu and Seed (2004), Tsukamato et al. (2004), etc.). Due to difficulties in the determination of input model parameters necessary for numerical simulations, semi-empirical models continue to establish the state of practice for the assessment of cyclicallyinduced reconsolidation (volumetric) settlements. Even the best of their kind of these models cannot produce, at the moment, reasonably precise estimates of postcyclic reconsolidation (volumetric) settlements.

Recently, Cetin et al. (2009b) has developed a new methodology based on their aforementioned semi-empirical post-cyclic volumetric strain estimation model. The proposed method was calibrated via 49 well-documented cyclically-induced ground settlement case histories from seven different earthquakes. Within the confines of that study, performance of the widely used methods of Tokimatsu and Seed (1984), Ishihara and Yoshimine (1992), Shamoto et al. (1998), Wu and Seed (2004) were comparatively evaluated. It was concluded that the proposed methodology, details of which will be given next, produced more accurate and precise settlement estimations compared to all other efforts.

Equation (19.16) constitutes the basis of the proposed method, and calculation of $N_{1,60, C S}$ and $C S R_{S S, 20,1-D, 1 \mathrm{~atm}}$ is the necessary first step. Next, a weighting scheme, linearly decreasing with depth, inspired after the recommendations of Iwasaki et al. (1982), is implemented. Aside from the better model fit it produced, the rationale behind the use of a depth weighting factor, is based on (i) upward seepage, triggering void ratio redistribution, and resulting in unfavorably higher void ratios for the shallower sublayers of soil layers, (ii) reduced induced shear stresses and number of shear stress cycles transmitted to deeper soil layers due to initial 
liquefaction of surficial layers, and (iii) possible arching effects due to non-liquefied soil layers. All these may significantly reduce the contribution of volumetric settlement of deeper soil layers to the overall ground surface settlement. It is assumed that the contribution of layers to surface settlement diminishes as the depth of layer increases, and beyond a certain depth $\left(z_{c r}\right)$ settlement of an individual layer cannot be traced at the ground surface. After statistical assessments, the optimum value of this threshold depth was found to be $18 \mathrm{~m}$. The proposed depth weighting factor $\left(D F_{i}\right)$ is defined in Eq. 19.22. Equivalent volumetric strain, $\varepsilon_{v, \text { eqv }}$, of the soil profile is estimated by Eq. 19.23 and the estimated settlement, $s_{\text {estimated }}$, of the profile is simply calculated as the product of $\varepsilon_{v, \text { eqv }}$. and the total thickness of the saturated cohesionless soil layers or sublayers, $\sum t_{i}$, as presented by Eq. 19.24. $s_{\text {estimated }}$ is further calibrated by $\theta$ for the estimation of field settlement values. In Eq. 19.25, $\sigma_{\varepsilon}$ term designates the standard deviation of the calibration model. Further discussion of the $\sigma_{\varepsilon}$ term is presented later in the manuscript.

$$
D F_{i}=1-\frac{d_{i}}{z_{c r}=18 m} \text {, where } d_{i} \text { is the mid-depth of each saturated cohesionless }
$$

soil layer from ground surface.

$$
\begin{gathered}
\varepsilon_{v, \text { eqv. }}=\frac{\sum \varepsilon_{v, i} \cdot t_{i} \cdot D F_{i}}{\sum t_{i} \cdot D F_{i}} \\
s_{\text {estimated }}=\varepsilon_{v, \text { eqv. }} \cdot \sum t_{i} \\
\ln \left(s_{\text {calibrated }}\right)=\ln \left(\theta \cdot s_{\text {estimated }}\right) \pm \sigma_{\varepsilon}
\end{gathered}
$$

In volumetric settlement assessment of the case histories, three cases were encountered regarding the application of $D F$ : (i) a very dense cohesionless soil layer $\left(N_{1,60, C S}>35\right)$ or bedrock or a cohesive soil layer underlying the volumetric settlement vulnerable cohesionless soil layer, (ii) cohesionless soil layer continuing beyond the critical depth of $18 \mathrm{~m}$ with or without available SPT profile, and (iii) cohesionless soil site where the depth of boring is less than $18 \mathrm{~m}$. For case (i), settlement calculations were performed till the depth to the top of the dense layer or bedrock or cohesive layer. For case (ii), potentially settlement vulnerable cohesionless layers beyond $18 \mathrm{~m}$ were simply ignored due to their limited contribution to the overall ground surface settlement. For case (iii), after confirming with the geological characteristics of soil site, for the soil sub-layers without an SPT value at a specific depth, SPT values were judgmentally extended beyond the maximum borehole depth to a depth of maximum $18 \mathrm{~m}$., based on available SPT blow-counts. Whenever a cohesive soil layer was encountered, it was assumed that cyclicallyinduced volumetric strain due to this layer was negligible. In addition, thickness of this layer was not considered in the calculation of $\varepsilon_{v, e q v}$.

For comparison purposes, each case history site (presented in detail in Bilge and Cetin 2007) was analyzed by using the methods of Tokimatsu and Seed (1984), Ishihara and Yoshimine (1992), Shamoto et al. (1998), Wu and Seed (2004) and finally the proposed method. The performance of the model predictions, expressed 
Table 19.1 Comparison of the performance of existing models

\begin{tabular}{lllll}
\hline Method & $\mathrm{R}^{2}$ & $\theta_{1}$ & $\sigma_{\varepsilon}$ & Elikelihood fxn \\
\hline Çetin et al. (2009b) & 0.64 & 1.15 & 0.61 & -19.8 \\
Tokimatsu and Seed (1984) & 0.33 & 1.45 & 1.05 & -31.1 \\
Ishihara and Yoshimine (1992) & 0.42 & 0.90 & 1.12 & -32.7 \\
Shamoto et al. (1998) & 0.36 & 1.93 & 1.36 & -36.7 \\
Wu and Seed (2004) & 0.33 & 0.98 & 0.71 & -22.9 \\
\hline
\end{tabular}

Fig. 19.21 Comparison between the measured and predicted ground settlements by Cetin et al. (2009b)

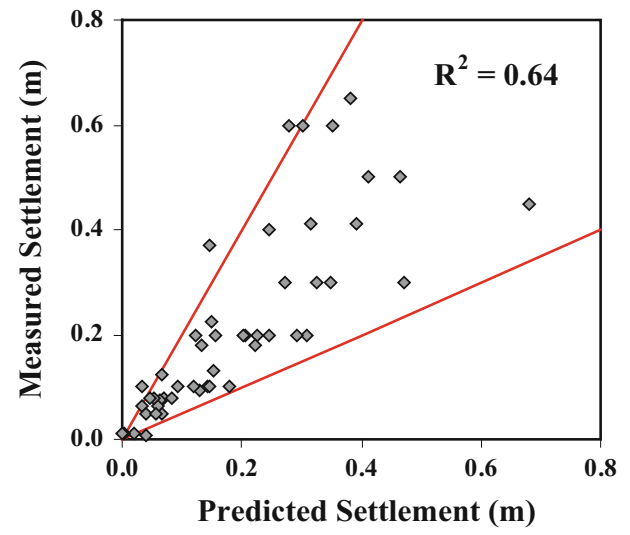

by Pearson product moment correlation coefficient, $\mathrm{R}^{2}$, is summarized in Table 19.1. As a better alternative, which enabled the assessment of the model (calibration) error, predictions of each method were compared probabilistically by using the maximum likelihood analysis. Results of these analysis, a calibration coefficient $\left(\theta_{1}\right)$ which enables the model to produce unbiased predictions in the average is determined. These values are also presented in the same table along with the value of maximum likelihood and standard deviation of the random model correction term. It should be noted that higher values of maximum likelihood and lower values of standard deviation are also indicators of a better model. As the values of the calibration coefficient, $\theta$, presented in Table 19.1 implies, existing methods of Shamoto et al. (1998), Tokimatsu and Seed (1984), and the proposed methodology under-predict the actual settlements by a factor of 1.91, 1.45 and 1.15, respectively. Similarly, Wu and Seed (2004), and Ishihara and Yoshimine (1992) over-predict settlements and need to be corrected by a factor of 0.98 and 0.90 . Wu and Seed (2004) procedure produces the most unbiased settlement predictions (i.e.: the mean of the estimated settlements is about equal to the mean of the observed settlements). However, in terms of the uncertainty (or scatter) of the predictions, $\mathrm{Wu}$ and Seed (2004) methodology is ranked to be second to last with an $\mathrm{R}^{2}$ value of 0.33 . After scaling with the calibration coefficient, $\theta$, the proposed model produces relatively the best predictions compared to the other four methods, also consistent with the $\mathrm{R}^{2}$ trends presented in Table 19.1.

Performance of the proposed model is also highlighted by Fig. 19.21 in which predicted and observed settlements are paired and shown on figures along with the 
1:2 and 1:0.5 boundary lines. Readers are referred to Cetin et al. (2009b) for the similar performance evaluation plots prepared for the other methods.

\subsubsection{Assessment of Lateral Spreading}

Lateral spreading is a liquefaction-induced deformation problem identified by surficial soil layers breaking into blocks that progressively slide downslope or toward a free face during and after earthquake shaking. As opposed to settlements, lateral ground deformations are generally more critical for the performance of overlying structures as well as of infrastructures due to their limited lateral resistance.

Currently available approaches for predicting the magnitude of lateral spreading ground deformations can be categorized as: (i) numerical analyses in the form of finite element and/or finite difference techniques (e.g., Finn et al. (1994), Arulanandan et al. (2000), and Liao et al. (2002)), (ii) soft computing techniques (e.g., Wang and Rahman (1999)), (iii) simplified analytical methods (e.g., Newmark (1965), Towhata et al. (1992), Kokusho and Fujita (2002), and Elgamal et al. (2003)), and (iv) empirical methods developed based on the assessment of either laboratory test data or statistical analyses of lateral spreading case histories (e.g., Hamada et al. (1986), Shamoto et al. (1998), and Youd et al. (2002)). Due to difficulties in the determination of input model parameters of currently existing numerical and analytical models, empirical and semi-empirical models continue to establish the state of practice for the assessment of liquefaction-induced lateral ground deformations.

Hamada et al.(1986), Youd and Perkins (1987), Rauch (1997), Shamoto et al. (1998), Bardet et al. (1999), and Youd et al. (2002), Kanibir (2003), Faris et al. (2006) introduced empirically-based models for the assessment of liquefaction-induced lateral spreading. With the exception of Shamoto et al. and Faris et al., these models were developed based on regression analyses of available lateral spreading case histories. The predictive approach of Shamoto et al. (1998) and Faris et al. (2006) employ laboratory-based estimates of liquefaction-induced limiting shear strains coupled with an empirical adjustment factor in order to relate these laboratory values to the observed field behavior. Among all of these models, in addition to the pioneering study of Hamada et al. (1986), widely accepted and used Youd et al. (2002), and laboratory-based and field- calibrated model of Faris et al. (2006) will be discussed in more detail next.

In 1986, Hamada et al. introduced a simple empirical equation for predicting liquefaction induced lateral ground deformations only in terms of ground slope and thickness of liquefied soil layer. This equation was based on the regression analysis of 60 earthquake case histories, mostly from Noshiro-Japan, and it was expressed as:

$$
D_{h}=0.75 \cdot H^{1 / 2} \cdot \theta^{1 / 3}
$$

where: $D_{h}$ is the predicted horizontal ground displacement $(\mathrm{m}), H$ is the thickness of liquefied zone (m), (when more than one sub-layer liquefies, $H$ is measured as the 
distance from the top-most to the bottom-most liquefied sub-layers including all intermediate sub-layers), and $\theta$ is the larger slope of either ground surface or liquefied zone lower boundary (\%). Despite its simplicity and ease of use, due to limited number of case histories which established the basis of the relationship, its use should be limited to only cases with similar conditions.

Starting in the early 1990s, Bartlett and Youd $(1992,1995)$ introduced empirical methods for predicting lateral spread displacements at liquefiable sites. The procedure of Youd et al. (2002) is a refinement of these early efforts and the new and improved predictive models for either (i) sloping ground conditions, or (ii) relatively level ground conditions with a "free face" towards which lateral displacements may occur, were developed through multi-linear regression of a case history database. The proposed predictive models for the sloping ground and "free face" conditions are given in Eqs. (19.27) and (19.28), respectively.

$$
\begin{aligned}
& \log D_{h}=-16.213+1.532 \cdot M_{w}-1.406 \cdot \log R^{*}-0.012 \cdot R+0.338 \cdot \log S+ \\
& 0.54 \cdot \log T_{15}+3.413 \cdot \log \left(100-F_{15}\right)-0.795 \cdot \log \left(D 50_{15}+0.1 \mathrm{~mm}\right) \\
& \log D_{h}=-16.713+1.532 \cdot M_{w}-1.406 \cdot \log R^{*}-0.012 \cdot R+0.592 \cdot \log W+ \\
& 0.54 \cdot \log T_{15}+3.413 \cdot \log \left(100-F_{15}\right)-0.795 \cdot \log \left(D 50_{15}+0.1 \mathrm{~mm}\right)
\end{aligned}
$$

where; $\mathrm{D}_{\mathrm{H}}$ is horizontal ground displacement in meters predicted by multiple linear regression model, $\mathrm{M}_{\mathrm{w}}$ is earthquake magnitude, $\mathrm{S}$ is the gradient of surface topography or ground slope $(\%), \mathrm{W}$ is the free-face ratio, defined as the height of the freeface divided by its distance to calculation point, $T_{15}$ is the thickness of saturated layers with SPT- $N_{1,60} \leq 15, F_{15}$ is the average fines content (particles $<0.075 \mathrm{~mm}$ ) in $T_{15}(\%), D 50_{15}$ is the average $D_{50}$ in $T_{15}$. $\mathrm{R}$ is the horizontal distance to the nearest seismic source or to nearest fault rupture $(\mathrm{km})$, and $\mathrm{R}^{*}$ is calculated according to following equation.

$$
R^{*}=R+R_{0} \text { and } R_{0}=10^{0.89 \cdot M_{w}-5.64}
$$

The empirical model of Youd et al. (2002) is widely used in the engineering profession. The performance of the model was also evaluated by Youd et al., as presented in Fig. 19.22. Reported $\mathrm{R}^{2}$ value of $83.6 \%$ is concluded to be sufficiently high. However, it should be noted that (i) an attenuation-like intensity measure in terms of magnitude and distance is adopted as opposed to an independent peak soil ground acceleration term, which further brings along the uncertainties in the predictions of these attenuation-like formulations into the lateral spreading predictions, (ii) zero lateral displacement was produced for soil sites composed of sublayers with $\left(\mathrm{N}_{1}\right)_{60}$ to be greater than 15 blows $/ 30 \mathrm{~cm}$. Moreover, the success rate at the displacement range of $0-3 \mathrm{~m}$, which is believed to be more critical compared to large displacement range from performance point of view, is not satisfactorily high. 


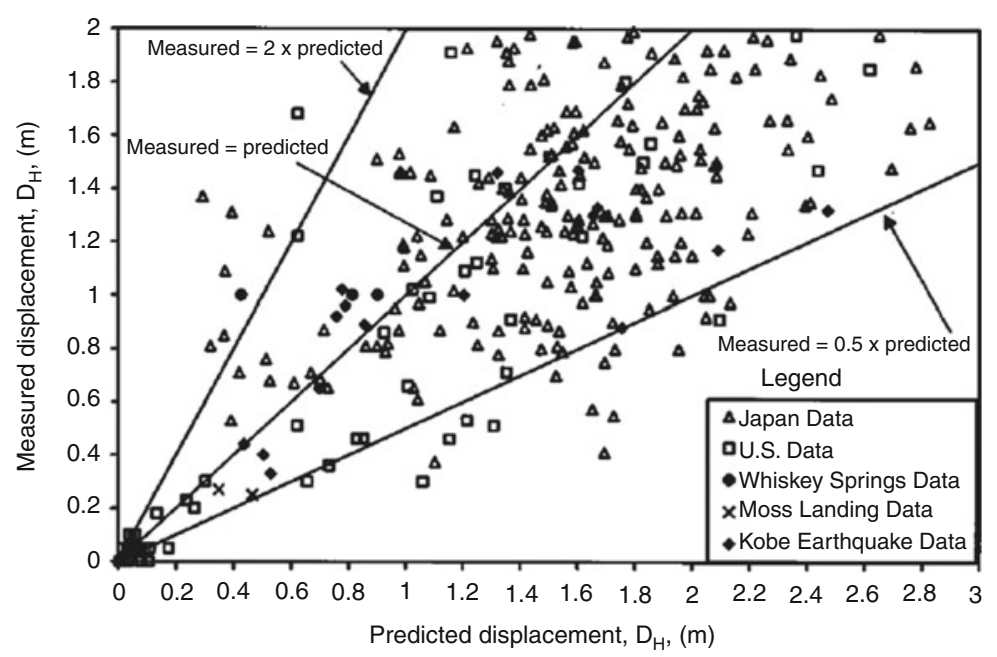

Fig. 19.22 Performance evaluation of Youd et al. (2002) lateral spreading prediction model

More recently, Faris et al. (2006) has presented the following semi-empirical model.

$$
H_{\max }=\exp \left(1.0443 \cdot \ln \left(D P I_{\max }\right)+0.0046 \cdot \ln \alpha+0.0029 \cdot M_{w}\right.
$$

where $H_{\max }$ is the lateral spreading in meters, $D P I_{\max }$ is the maximum cyclic shear strain potential (to be determined according to Wu et al. 2003; Fig. 19.16), $\alpha$ is the slope or free-face ratio, and $M_{w}$ is the earthquake magnitude. Faris et al. has similarly performed a performance evaluation study results of which is presented in Fig. 19.23. Note that this framework takes into account the cyclic shear straining potential of soils, which is a physically meaningful term. However, similar to the method of Youd et al., the prediction success rate of this mode is not very high at the displacement range of $0-3 \mathrm{~m}$.

Although these models are the best of their kind, due to large uncertainties associated with input parameters as well as model errors, more efforts are needed to achieve more precise models in the prediction of lateral spread-type soil deformations. Thus, practicing engineers are warned to be aware of the large uncertainty involved in the predictive models. A probabilistic approach addressing these sources of uncertainties could be a robust decision making approach and is strongly recommended.

\subsubsection{Seismic Deformation Response of Silt and Clay Mixtures}

Ohara and Matsuda (1988) presented one of the pioneering efforts, as part of which they expressed post-cyclic volumetric strain $\left(\varepsilon_{v, p c}\right)$ as a function of excess pore 
Fig. 19.23 Performance evaluation of Faris et al. (2006) lateral spreading prediction model

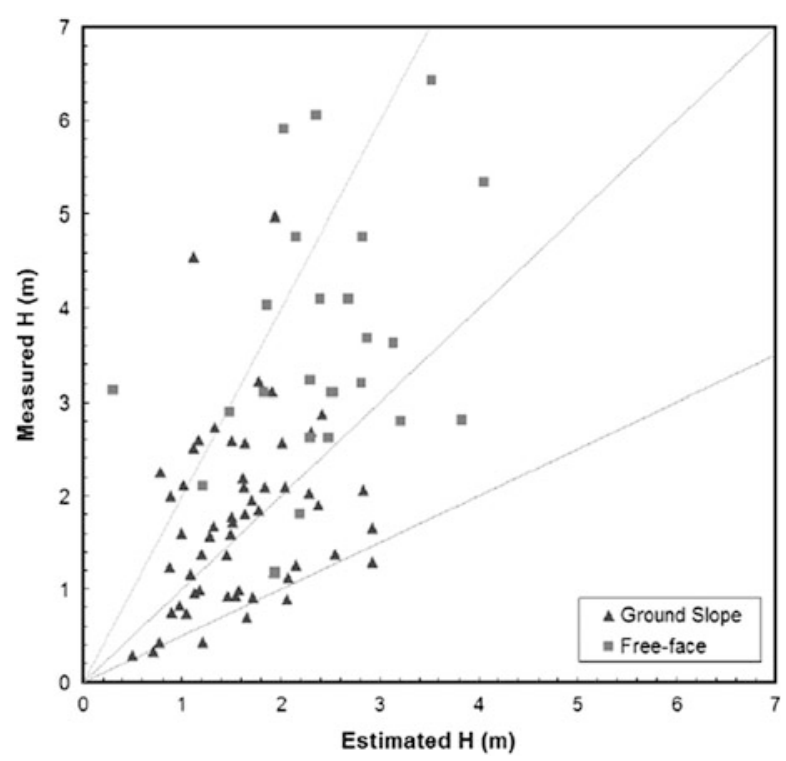

water pressure ratio $\left(r_{u}\right)$, initial void ratio $\left(e_{0}\right)$ and compression index induced by cyclic loading $\left(C_{d y n}\right)$ as given by Eq. (19.31).

$$
\varepsilon_{v, p c}=\frac{C_{d y n}}{1+e_{0}} \cdot \log \left(\frac{1}{1-r_{u}}\right)
$$

The relationship between $C_{d y n}$ and OCR along with compression $\left(\mathrm{C}_{\mathrm{c}}\right)$ and swelling $\left(\mathrm{C}_{\mathrm{s}}\right)$ indices were given by Ohara and Matsuda as presented in Fig. 19.24. The authors also presented a model for prediction of cyclically-induced excess pore water pressure. However, this model is defined in terms of a large number of material coefficients which requires cyclic testing for each specific material. This limits the practical value of both $r_{u}$ and also $\varepsilon_{v, p c}$ models significantly.

Yasuhara et al. (1992) has performed an experimental study and stated that the ratio of $\mathrm{C}_{\mathrm{dyn}}$ to $\mathrm{C}_{\mathrm{s}}$ was approximately equal to 1.5 . Unfortunately, pore pressure generation response and corollary issues were not addressed by the researchers. Later, Yasuhara et al. (2001) proposed a design methodology for the assessment of post-cyclic volumetric settlements (i.e. strains) based on the early findings of Yasuhara's research teams (Yasuhara and Andersen 1991; Yasuhara et al. 1992; Yasuhara and Hyde 1997). As an input requirement of the methodology, the estimation of excess pore pressure is required, and authors recommended 2-D or 3-D dynamic numerical analysis for the determination of excess pore water pressure distribution within the soil media. The need of a 2-D or 3-D numerical analysis for the prediction of excess pore water pressure contradicts with authors' intention of producing a practical design procedure.

Recently, Hyde et al. (2007) studied post-cyclic recompression stiffness and cyclic strength of low plasticity silts. Based on cyclic tests results and 1-D 
Fig. 19.24 Relationship between $\mathrm{C}_{\mathrm{dyn}}$ and OCR (After Ohara and Matsuda 1988)

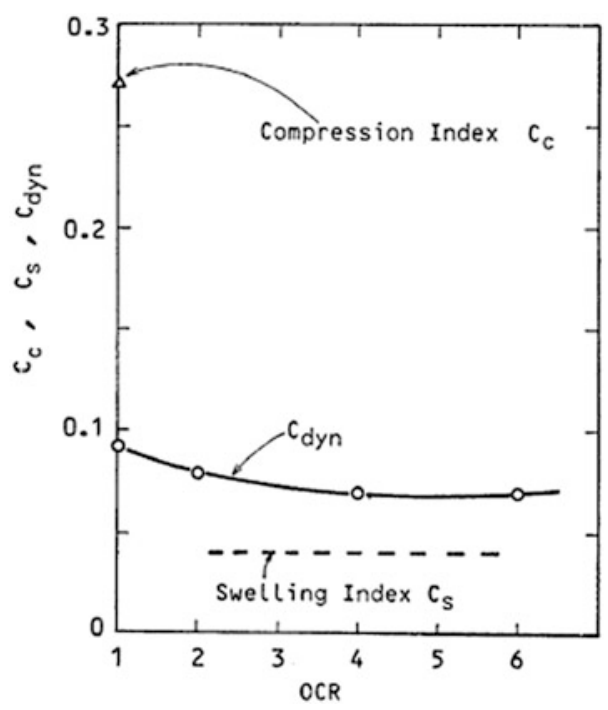

consolidation theory, authors proposed an expression in which $\varepsilon_{v, p c}$ was expressed as a function of initial sustained deviator stress ratio $\left(q_{s} / p_{c}^{\prime}\right)$, post-cyclic axial strain $\left(\varepsilon_{a, p c}\right)$ and void ratio $(e)$ of the tested material as follows:

$$
\varepsilon_{v, p c}=\frac{1.74}{e^{1,71} \cdot\left(q_{s} / p_{c}^{\prime}\right)} \cdot \varepsilon_{a, p c}^{0.461}
$$

Hyde et al. (2007) recommended an alternative approach by modeling $\varepsilon_{v, p c}$ as a function axial strain rather than excess pore water pressure. This approach has been used for saturated sandy soils by various researchers (e.g. Tatsuoka et al. 1984; Ishihara and Yoshimine 1992) but was not widely adopted for fine-grained soils, possibly due to absence of tools for predicting resulting axial strains. This fact also limits extensive use Hyde et al.'s model.

As presented so far, most of the attention has focused on the quantification of post-cyclic volumetric (reconsolidation) strains and cyclic shear straining response was not extensively studied. Except the theoretically-based attempts (e.g. Wilson and Greenwood 1974; Hyde and Brown 1976) proposed in the mid-1970s for the prediction of plastic deformation of plastic fine-grained subgrade soils under repeated loading, Hyodo et al. (1994) presented one of the few remarkable effort. Hyodo et al. (1994) attempted to correlate cyclically-induced shear strains with residual axial strains.

Considering the significant gap in the literature, the authors of this manuscript have performed a comprehensive experimental-based study. Using the results of cyclic and static triaxial test results on "undisturbed" silt and clay mixtures, following semi-empirical models are developed for the assessment cyclic maximum shear and residual strain potential of silt and clay mixtures. 


$$
\begin{aligned}
& \ln \left(\gamma_{\max }\right)=\ln \left[\begin{array}{l}
9.939 \cdot \frac{26.163\left(0.995 \cdot \frac{w_{c}}{L L}\right)}{\ln (P I)} \cdot\left(1-0.076 \cdot \ln \left(\frac{21.08}{P I}\right)\right) \cdot \\
25.807-\sqrt{\left(\frac{\tau_{s t}}{s_{u}}-5.870\right)^{2}+\left(\frac{\tau_{c y c}}{s_{u}}-(-25.085)\right)^{2}}
\end{array}\right] 0.537 \\
& \ln \left(\gamma_{\text {res }}\right)=\ln \left[\gamma_{\max } \cdot\left(\begin{array}{l}
0.845 \cdot \gamma_{\max }-0.332+0.404 \cdot S R R^{1.678} \\
+0.375 \cdot(\ln P I)^{0.446}+(7.564) \cdot\left(\frac{\tau_{s t}}{s_{u}}\right)^{9.249}-0.959
\end{array}\right)^{1.438}\right] \\
& \pm 0.586
\end{aligned}
$$

where, $\tau_{s t} / s_{u}$ and $\tau_{c y c} / s_{u}$ present the static and cyclic shear stress ratio for cohesive soils, respectively; whereas, SSR is the ratio of static to cyclic shear stresses (i.e. $\tau_{s t} / \tau_{c y c}$ ).

The recommended framework requires index test results along with the undrained shear strength $\left(s_{u}\right)$ of soils, which could be determined via laboratory or in-situ tests Ratio of $\tau_{\text {cyc }} / s_{u}$ presents the soil strength used by seismic loading nd it could be estimated by either the simplified procedure of Seed and Idriss (1971) or site response assessments; whereas, ratio of $\tau_{\mathrm{st}} / \mathrm{s}_{\mathrm{u}}$ presents the soil strength used by available static shear stresses, if there exists any. This latter term could be estimated via simple analytical closed form elastic stress distribution solutions.

Assessment of the post-cyclic volumetric (reconsolidation) strains is the other issue which needs to be addressed. For the purpose, a consolidation-theory based approach is followed; however, unlike earlier efforts, $\mathrm{C}_{\mathrm{dyn}}$ is defined as a function of over consolidation ratio (OCR), maximum cyclic shear strain potential under selected loading scenario and plasticity index of the soil, as presented in Eq. (19.35). As outlined before, estimation of excess pore water pressure constitutes the integral part of the problem, and by probabilistic assessment of the existing test data, a new cyclic-pore water pressure model was also developed for silt and clay mixtures as presented in Eq. (19.36).

$$
C_{\text {dinamik }}=\left(1+\frac{0.53 \cdot O C R^{2}-3.233 \cdot O C R+5.927}{1+1.118 \cdot \gamma_{\max }-0.404+0.829 \cdot \ln P I}\right) \cdot C_{r}
$$


Fig. 19.25 Recommended maximum shear strain boundaries for $\mathrm{wc} / \mathrm{LL}=1.0$ and $\mathrm{PI}=10$

Fig. 19.26 Recommended residual shear strain boundaries
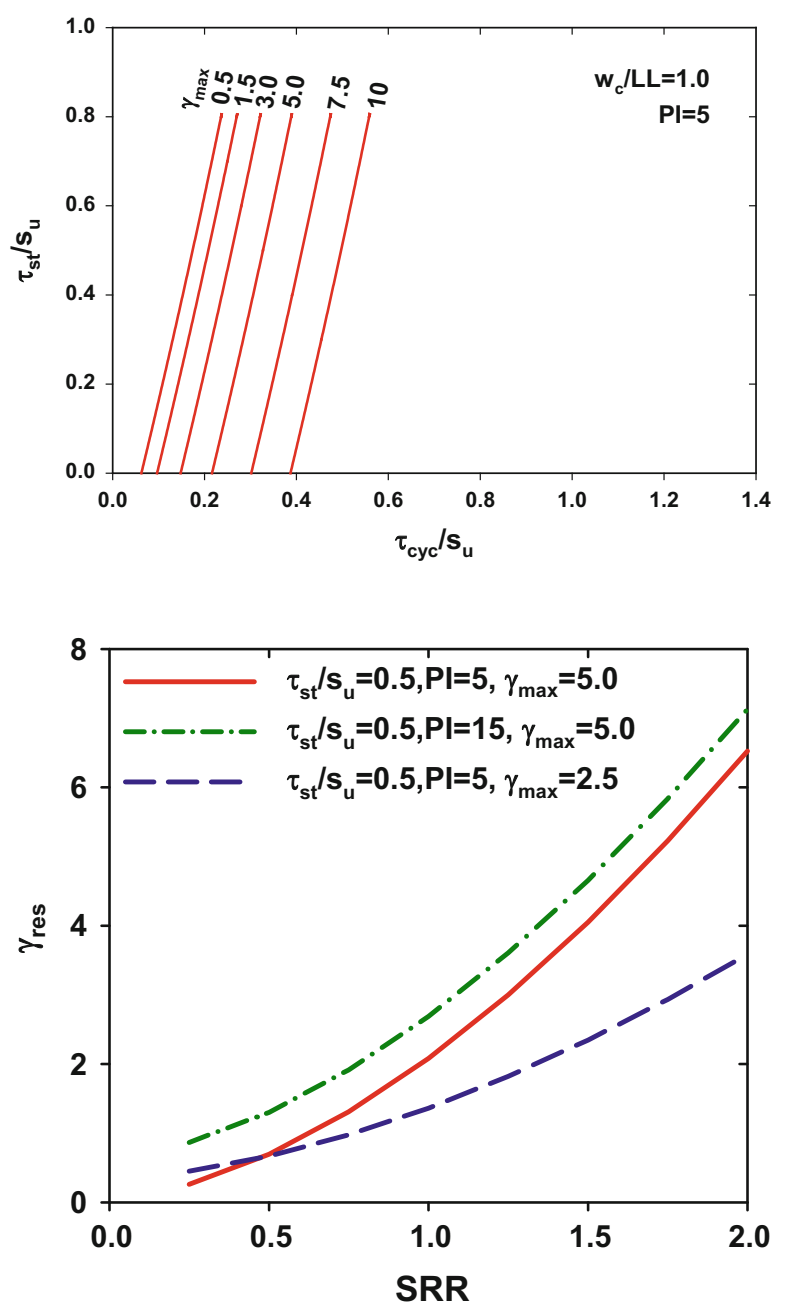

$$
\begin{aligned}
\ln \left(r_{u, N}\right) & =\ln \left[1-\exp \left(\frac{\gamma_{\max , N}}{-1.991 \cdot \exp (0.02 \cdot P I-0.05 \cdot L I) \cdot\left[\ln \left(\frac{F C}{0.01}\right)\right]^{0.328}}\right)\right] \\
& \pm\left(\frac{1}{\gamma_{\max , N}^{0.378}+0.506}\right)
\end{aligned}
$$

Although close form expressions are easier and more practical, the graphical solutions are also presented as given in Figs. 19.25, 19.26, and 19.27, to provide an 
Fig. 19.27 Recommended values of $\mathrm{C}_{\mathrm{dyn}}$ as a function of OCR and $\gamma_{\max }$

Fig. 19.28 Performance evaluation of the proposed post-cyclic volumetric strain prediction model
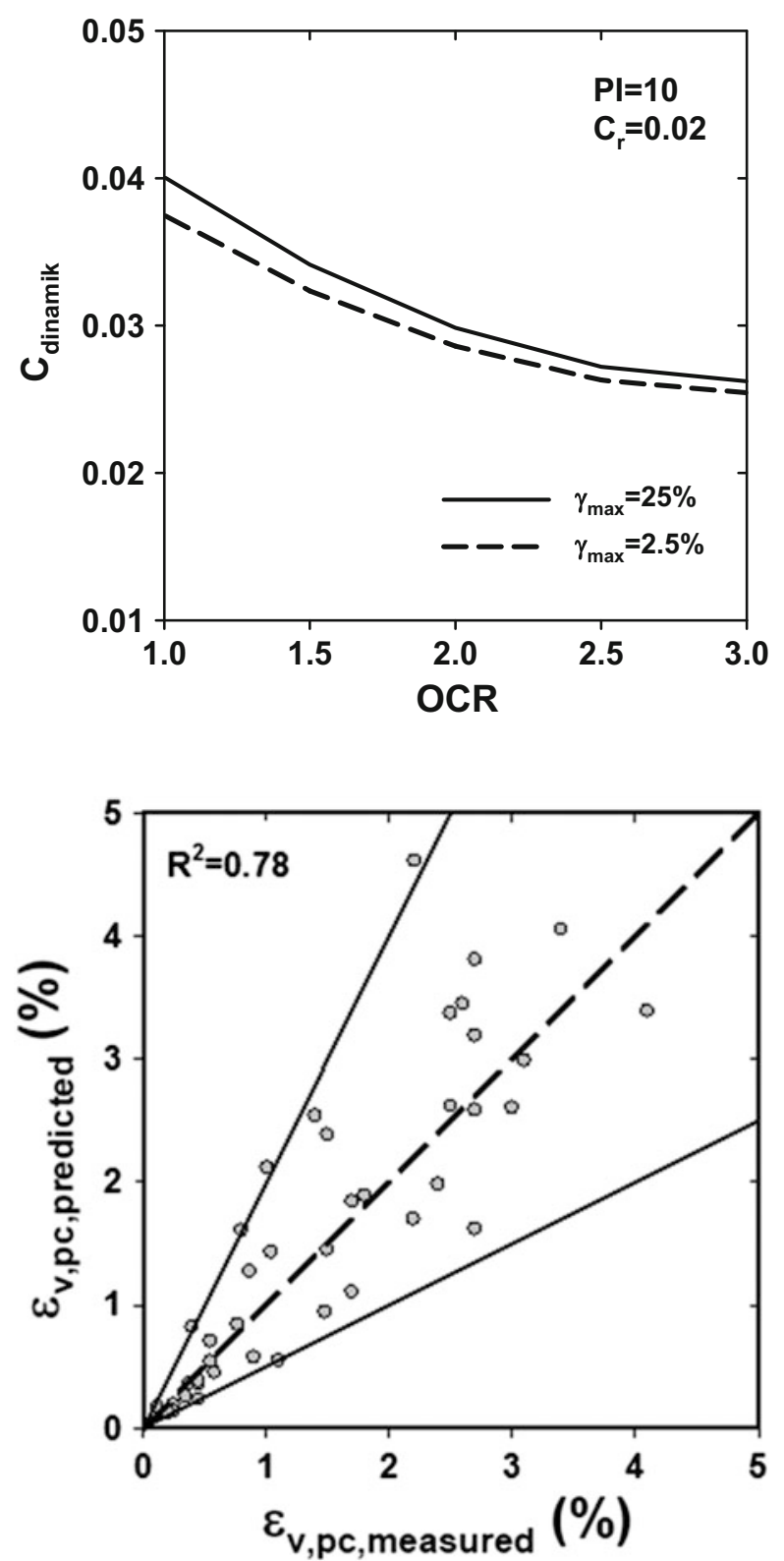

insight to the users. More detailed discussion on database compilation and model development phase are available in Bilge (2010).

The performance of these models was evaluated based on experimental measurements and presented in detail by Bilge (2010). Evaluation of the post-cyclic volumetric straining model is presented by Fig. 19.28, and it is concluded that the 
laboratory measurements could be estimated with a high success rate over a wide strain range. Yet case history based calibration is still needed.

\subsection{Summary and Concluding Remarks}

Within the confines of this chapter, a summary of current state of practice in seismic soil liquefaction engineering was presented. Since seismic soil liquefaction engineering problems involve a five step assessment framework including the assessment of (i) "triggering" or initiation of soil liquefaction, (ii) post-liquefaction strength and overall post-liquefaction stability, (iii) expected liquefaction-induced deformations and displacements, (iv) the consequences of these deformations and displacements, (v) mitigation alternatives, if necessary, the discussion scheme also followed the footprints of the first four steps of liquefaction engineering. Considering the increasing popularity of performance-based design trends, special emphasis was given on the assessment of cyclic strength and deformation performance of both cohesionless and cohesive soils. New frameworks were introduced and some recommendations listed for the practitioners. However, no conclusion can be complete without emphasizing the need for further research aiming to understand cyclic deformation response of soils.

Acknowledgements Some of the authors' findings and conclusions were compiled from their research performed with a number of collaborators including but not limited to Drs. R. B. Seed, R.E.S. Moss, A.M. Kammerer, J. Wu, J. M. Pestana, M. F. Riemer, R.E. Kayen, L.F. Harder Jr., A. Der Kiureaghian, K. Tokimatsu, J. Bray, R. Sancio, and T. L. Youd. Their contributions are strongly acknowledged and appreciated.

Open Access This chapter is distributed under the terms of the Creative Commons Attribution Noncommercial License, which permits any noncommercial use, distribution, and reproduction in any medium, provided the original author(s) and source are credited.

\section{References}

Andrews DC, Martin GR (2000) Criteria for liquefaction of silty sands. In: Proceedings of the 12th world conference on earthquake engineering, Auckland, New Zealand

Andrus RD, Stokoe KH, Roesset JM (1991) Liquefaction of gravelly soil at Pence Ranch during the 1983 Borah Peak, Idaho earthquake. In: First international conference on soil dynamics and earthquake engineering V, Karlsruhe, Germany

Arulanandan K, Li XS, Sivathasan K (2000) Numerical simulation of liquefaction-induced deformation. J Geotech Eng ASCE 126(7):657-666

Bardet JP, Mace N, Tobita T (1999) Liquefaction-induced ground deformation and failure. A report to PEER/PG\&E, Task 4A - Phase 1, Civil Engineering Department, University of Southern California, Los Angeles 
Bartlett SF, Youd TL (1992) Empirical analysis of horizontal ground displacement generated by liquefaction-induced lateral spreads. Technical report no. NCEER-92-0021, National Center for Earthquake Engineering Research, State University of New York, Buffalo, pp 5-14-15

Bartlett SF, Youd TL (1995) Empirical prediction of liquefaction-induced lateral spread. J Geotech Eng 121(4):316-329

Bilge HT (2010) Cyclic volumetric and shear strain responses of fine-grained soils. Ph.D. dissertation, Middle East Technical University, Ankara

Bilge HT, Cetin KO (2007) Field performance case histories for the assessment of cyclicallyinduced reconsolidation (volumetric) settlements. METU - EERC Report No. 07 - 01, Middle East Technical University Earthquake Engineering Research Center, Ankara

Booker JR, Rahman MS, Seed HB (1976) GADFLEA - A computer program for the analysis of pore pressure generation and dissipation during cyclic or earthquake loading. Report No. EERC 76-24, University of California at Berkeley, Berkeley, California

Boulanger RW, Idriss IM (2006) Liquefaction susceptibility criteria for silts and clays. J Geotech Geoenviron Eng ASCE 132(11):1413-1426

Boulanger RW, Idriss IM (2007) Evaluation of cyclic softening in silts and clays. J Geotech Geoenviron Eng ASCE 133(6):641-652

Bray JD, Sancio RB (2006) Assessment of liquefaction susceptibility of fine-grained soils. J Geotech Geoenviron Eng 132(9):1165-1177

Castro G, Christian JT (1976) Shear strength of soils and cyclic loading. J Geotech Eng 102 (9):887-894

Cetin KO (2000) Reliability -based assessment of seismic soil liquefaction initiation hazard. Ph.D. dissertation, University of California, Berkeley, California

Cetin KO, Seed RB (2002) Nonlinear shear mass participation factor, rd for cyclic shear stress ratio evaluation. J Soil Dyn Earthquake Eng 24(2):103-113

Cetin KO, Seed RB, Der Kiureghian A, Tokimatsu K, Harder LF Jr, Kayen RE, Moss RES (2004) SPT-based probabilistic and deterministic assessment of seismic soil liquefaction potential. J Geotech Geoenviron Eng 130(12):1314-1340

Cetin KO, Bilge HT, Wu J, Kammerer A, Seed RB (2009a) Probabilistic models for cyclic straining of saturated clean sands. J Geotech Geoenviron Eng ASCE 135(3):371-386

Cetin KO, Bilge HT, Wu J, Kammerer A, Seed RB (2009b) Probabilistic model for the assessment of cyclically-induced reconsolidation (volumetric) settlements. J Geotech Geoenviron Eng ASCE 135(3):387-398

Davis AP, Poulos SJ, Castro G (1988) Strengths back figured from liquefaction case histories. In: Second international conference on case histories in geotechnical engineering, vol 3, St. Louis, pp 1693-1701

Evans MD (1987) Undrained cyclic triaxial testing of gravels: the effect of membrane compliance. Ph.D. dissertation, University of California, Berkeley

Elgamal A, Yang Z, Parra E, Ragheb A (2003) Modeling of cyclic mobility in saturated cohesionless soils. Int J Plast 19(6):883-905

Faris AT, Seed RB, Kayen RE, Wu J (2006) A semi-empirical model for the estimation of maximum horizontal displacement due to liquefaction-induced lateral spreading. In: Proceedings of the 8th US national conference on earthquake engineering, San Francisco, CA, USA, Paper No. 1323

Finn WDL, Lee KW, Martin GR (1977) An effective stress model for liquefaction. J Geotech Eng 103(6):517-533

Finn LW, Ledbetter RH, Guoxi WU (1994) Liquefaction in silty soils: design and analysis. Ground failures under seismic conditions. ASCE Geotechnical Special Publication No. 44, pp 51-79

Hamada M, Yasuda S, Isoyama R, Emoto K (1986) Study on liquefaction induced permanent ground displacement. Report for the Association for the Development of Earthquake Prediction, Japan

Harder LF Jr (1988) Use of penetration tests to determine the cyclic loading resistance of gravelly soils during earthquake shaking. Ph.D. dissertation, University of California, Berkeley 
Harder LF Jr, Seed HB (1986) Determination of penetration resistance for coarse-grained soils using the Becker Hammer Drill. Earthquake Engineering Research Center, Report No. UCB/ EERC-86/06, University of California, Berkeley

Hyde AFL, Brown SF (1976) The plastic deformation of a silty clay under creep and repeated loading. Géotechnique 26(1):173-184

Hyde AFL, Higuchi T, Yasuhara K (2007) Postcyclic recompression, stiffness, and consolidated cyclic strength of silt. J Geotech Geoenviron Eng ASCE 133(4):416-423

Hyodo M, Yamamoto Y, Sugiyama M (1994) Undrained cyclic shear behavior of normally consolidated clay subjected to initial static shear stress. Soils Found 34(4):1-11

Idriss IM, Boulanger R (2006) Semi-empirical procedures for evaluating liquefaction potential during earthquakes. Soil Dyn Earthquake Eng 26(2-4):115-130

Idriss IM, Boulanger RW (2007) SPT- and CPT-based relationships for the residual shear strength of liquefied soils. In: Pitilakis KD (ed) Earthquake geotechnical engineering, 4th international conference on earthquake geotechnical engineering - invited lectures. Springer, Dordrecht, pp $1-22$

Ishihara K (1985) Stability of natural deposits during earthquakes. In: Proceedings of the eleventh international conference on soil mechanics and foundation engineering, San Francisco

Ishihara K (1993) Liquefaction and flow failure during earthquakes. Geotechnique 43(3):351-415

Ishihara K, Yoshimine M (1992) Evaluation of settlements in sand deposits following liquefaction during earthquakes. Soils Found 32(1):173-188

Iwasaki T, Arakawa T, Tokida K (1982) Standard penetration test and liquefaction potential evaluation. Proceedings, international conference of soil dynamics and earthquake engineering, vol 2, Southampton, pp 925-941

Kanibir A (2003) Investigation of the lateral spreading at Sapanca and suggestion of empirical relationships for predicting lateral spreading. M.Sc. thesis, Department of Geological Engineering, Hacettepe University, Ankara

Kayen R, Moss RES, Thompson EM, Seed RB, Cetin KO, Der Kiureghian A, Tanaka Y, Tokimatsu K (2013) Probabilistic and deterministic assessment of seismic soil liquefaction potential by shear wave velocity. ASCE J Geotech Geoenviron Eng 139(3):407-419

Kishida H (1966) Damage to reinforced concrete buildings in Niigata city with special reference to foundation engineering. Soils Found 2:38-44

Kokusho T, Fujita K (2002) Site investigations for involvement of water films in lateral flow in liquefied ground. J Geotech Geoenviron Eng 128(11):917-925

Koutsoftas DC (1978) Effect of cyclic loads on undrained shear strength of two marine clays. J Geotech Eng ASCE 104(5):609-620

Lee KL, Albeisa A (1974) Earthquake induced settlements in saturated sands. J Geotech Eng 100 (GT4):387-406

Lee KL, Focht JA (1976) Strength of clay subjected to cyclic loading. Marine Geotech 1(3):165-185

Liao SSC, Veneziano D, Whitman RV (1988) Regression models for evaluating liquefaction probability. J Geotech Eng 114(4):389-411

Liao T, McGillivray A, Mayne PW, Zavala G, Elhakim A (2002) Seismic ground deformation modeling. Fianl report for MAE HD-7a (year 1), Geosystems Engineering/School of Civil \& Environmental Engineering, Georgia Institute of Technology, Atlanta, 12 Dec 2002

Liyanathirana DS, Poulos HG (2002) A numerical model for dynamic soil liquefaction analysis. Soil Dyn Earthquake Eng 22(9-12):1007-1015

Martin GR, Finn WDL, Seed HB (1975) Fundamentals of liquefaction under cyclic loading. J Geotech Eng Div 101(5):423-438

Matsui T, Ohara H, Itou N (1980) Cyclic stress - strain history and shear characteristics of clay. J Geotech Eng 106(10):1101-1120

Moss RES, Seed RB, Kayen RE, Stewart JP, Kiureghian AD, Cetin KO (2006) CPT-based probabilistic and deterministic assessment of in situ seismic soil liquefaction potential. J Geotech Geoenviron Eng 132(8):1032-1051 
National Center for Earthquake Engineering Research (NCEER) (1997) In: Youd TL, Idriss IM (eds) Proceedings of the NCEER workshop on evaluation of liquefaction resistance of soils. Technical report no. NCEER-97-0022

Newmark NM (1965) Effects of earthquakes on embankments and dams. Géotechnique 15(2):139-160

Ohara S, Matsuda H (1988) Study on the settlement of saturated clay layer induced by cyclic shear. Soils Found 28(3):103-113

Okamura T (1971) The variation of mechanical properties of clay samples depending on its degree of disturbance: specialty session; quality in soil sampling. In: Proceedings of the 4th Asian regional conference on SMFE, vol 1, pp 73-81

Olson SM, Stark TD (2002) Liquefied strength ratio from liquefaction case histories. Can Geotech J 39:629-647

Perlea V (2000) Liquefaction of cohesive soils. In: Pak RYS, Yamamura J (eds) Liquefaction of cohesive soils. Soil dynamics and liquefaction 2000, Geotechnical Special Publications (GSP) GSP 107, pp 58-76

Poulos SJ, Castro G, France JW (1985) Liquefaction evaluation procedure. J Geotech Eng ASCE 111(6):772-792

Rauch AF (1997) An empirical method for predicting surface displacements due to liquefactioninduced lateral spreading in earthquakes. Ph.D. dissertation, Virginia Polytechnic Institute and State University, Blacksburg, Virginia

Robertson PK, Wride CE (1998) Evaluating cyclic liquefaction potential using the cone penetration test. Can Geotech J 35(3):442-459

Robertson PK, Woeller DJ, Finn WDL (1992) Seismic cone penetration test for evaluating liquefaction potential under cyclic loading. Can Geotech J 29:686-695

Sangrey DA, France JW (1980) Peak strength of clay soils after a repeated loading history. In: Proceedings of the international symposium soils under cyclic and transient loading, vol 1 , pp 421-430

Seed HB (1983) Earthquake-resistant design of earth dams. In: Proceedings of the symposium on seismic design of embankments and caverns. ASCE, Philadelphia

Seed HB (1987) Design problems in soil liquefaction. J Geotech Eng ASCE 113(8):827-845

Seed RB, Harder LF Jr (1990) SPT-based analysis of cyclic pore pressure generation and undrained residual strength. In: Proceedings of the H. B. Seed memorial symposium, May 1990

Seed HB, Idriss IM (1971) Simplified procedure for evaluating soil liquefaction potential. J Soil Mech Found Div ASCE 97(SM9):1249-1273

Seed HB, Idriss IM (1982) Ground motions and soil liquefaction during earthquakes. Earthquake Engineering Research Institute, Berkeley, 134 pp

Seed HB, Martin GR, Lysmer J (1976) Pore-water pressure changes during soil liquefaction. J Geotech Eng 102(GT4):323-346

Seed HB, Tokimatsu K, Harder LF, Chung RM (1984) The influence of SPT procedures in soil liquefaction resistance evaluations. Earthquake Engineering Research Center Report No. UCB/EERC-84/15, University of California, Berkeley

Seed HB, Tokimatsu K, Harder LF, Chung RM (1985) The influence of SPT procedures in soil liquefaction resistance evaluations. J Geotech Eng 111(12):1425-1445

Seed HB, Seed RB, Harder LF, Jong H-L (1989) Re-evaluation of the Lower San Fernando Dam: Report 2, examination of the post-earthquake slide of February 9, 1971. US. Army Corps of Engineers Contract Report GL-89-2, US. Amy Corps of Engineers Waterways Experiment Station, Vicksburg, Mississippi

Seed RB, Cetin KO, Moss RES, Kammerer AM, Wu J, Pestana JM, Riemer MF (2001) Recent advances in soil liquefaction engineering and seismic site response evaluation. In: 4th international conference on recent advances in geotechnical earthquake engineering and soil dynamics, San Diego

Seed RB, Cetin KO, Moss RES, Kammerer AM, Wu J, Pestana JM, Riemer MF, Sancio RB, Bray RB, Kayen RE, Faris A (2003) Recent advances in soil liquefaction engineering: a unified and 
consistent framework. Report No. EERC 2003-06, Earthquake Engineering Research Center, University of California, Berkeley

Shamoto Y, Zhang JM, Tokimatsu K (1998) Methods for evaluating residual post-liquefaction ground settlement and horizontal displacement. Special Issue on the Geotechnical Aspects of the January 171995 Hyogoken-Nambu Earthquake, No. 2, pp 69-83

Sherif MA, Ishibashi I, Tsuchiya C (1977) Saturation effects on initial soil liquefaction. J Geotech Eng Div ASCE 103(8):914-917

Stark TD, Mesri G (1992) Undrained shear strength of liquefied sands for stability analysis. J Geotech Eng Div ASCE 118(11):1727-1747

Tatsuoka F, Sasaki T, Yamada S (1984) Settlement in saturated sand induced by cyclic undrained simple shear. In: 8th world conference on earthquake engineering, vol 3, San Francisco, CA, USA, pp 95-102

Thiers GR, Seed HB (1969) Strength and stress-strain characteristics of clays subjected to seismic loads. ASTM STP 450, symposium on vibration effects of earthquakes on soils and foundations, ASTM, pp 3-56

Tokimatsu K, Seed HB (1984) Simplified procedures of the evaluation of settlements in clean sands. Report No. UCB/GT-84/16, University of California, Berkeley, CA

Toprak S, Holzer TL, Bennett MJ, Tinsley JC (1999) CPT- and SPT-based probabilistic assessment of liquefaction potential. In: Proceedings of the 7th US-Japan workshop on earthquake resistant design of lifeline facilities and countermeasures against liquefaction, Seattle

Towhata I, Sasaki Y, Tokida K-I, Matsumoto H, Tamari Y, Yamada K (1992) Prediction of permanent displacement of liquefied ground by means of minimum energy principle. Soils Found JSSMFE 32(3):97-116

Tsukamato Y, Ishihara K, Sawada S (2004) Settlement of silty sand deposits following liquefaction during earthquakes. Soils Found 44(5):135-148

Ue S, Yasuhara K, Fujiwara H (1991) Influence of consolidation period on undrained strength of clays. Ground Construct 9(1):51-62

Van Eekelen HAM, Potts DM (1978) The behaviour of Drammen clay under cyclic loading. Géotechnique 28:173-196

Wang W (1979) Some findings in soil liquefaction. Report Water Conservancy and Hydro-electric Power Scientific Research Institute, Beijing, China, pp 1-17

Wang JG, Rahman MS (1999) A neural network model for liquefaction-induced horizontal ground displacement. Soil Dyn Earthquake Eng 18:555-568

Wilson NE, Greenwood JR (1974) Pore pressure and strains after repeated loading in saturated clay. Can Geotech J 11:269-277

Wride CE, Mcroberts EC, Robertson PK (1999) Reconsideration of case histories for estimating undrained shear strength in sandy soils. Can Geotech J 36(5):907-933

Wu J, Seed RB (2004) Estimating of liquefaction-induced ground settlement (case studies). In: Proceedings of the fifth international conference on case histories in geotechnical engineering, Paper 3.09, New York, NY, USA

Wu J, Seed RB, Pestana JM (2003) Liquefaction triggering and post liquefaction deformations of Monterey 0/30 sand under uni-directional cyclic simple shear loading. Geotechnical Engineering Research report no. UCB/GE-2003/01, University of California, Berkeley, CA

Yasuhara K (1994) Post-cyclic undrained strength for cohesive soils. J Geotech Eng ASCE 120 (11):1961-1979

Yasuhara K, Andersen KH (1991) Post-cyclic recompression settlement of clay. Soils Found 31(1):83-94

Yasuhara K, Hyde AFL (1997) Method for estimating post-cyclic undrained secant modulus of clays. J Geotech Geoenviron Eng 123(3):204-211

Yasuhara K, Fujiwara H, Hirao K, Ue S (1983) Undrained shear behavior of quasioverconsolidated clay induced by cyclic loading. In: Proceedings of the IUTAM symposium, Seabed Mechanics, pp 17-24 
Yasuhara K, Hirao K, Hyde AFL (1992) Effects of cyclic loading on undrained strength and compressibility of clay. Soils Found 32(1):100-116

Yasuhara K, Murakami S, Toyota N, Hyde AFL (2001) Settlements in fine-grained soils under cyclic loading. Soils Found 41(6):25-36

Youd TL, Noble SK (1997) Liquefaction criteria based on statistical and probabilistic analyses. In: Proceedings of the NCEER workshop on evaluation of liquefaction resistance of soils, National Center for Earthquake Engineering Research, State University of New York at Buffalo, pp 201-215

Youd TL, Perkins JB (1987) Map showing liquefaction susceptibility of San Mateo County. U.S. Geological Survey, California, Map I-1257-G

Youd TL, Idriss IM, Andrus RD, Arango I, Castro G, Christian JT, Dobry R, Finn WDL, Harder LF Jr, Hynes ME, Ishihara K, Koester JP, Liao SC, Marcuson WF, Martin GR, Mitchell JK, Moriwaki Y, Power MS, Robertson PK, Seed RB, Stokoe KH (2001) Liquefaction resistance of soils: Summary report from the 1996 NCEER and 1998 NCEER/NSF workshops on evaluation of liquefaction resistance of soils. J Geotech Geoenviron Eng, ASCE 127(10):817-833

Youd TL, Hansen CM, Bartlett SF (2002) Revised multilinear regression equations for prediction of lateral spread displacement. J Geotech Geoenviron Eng ASCE 128:1007-1017

Zhang G, Robertson PK, Brachman RWI (2002) Estimating liquefaction-induced ground settlements from CPT for level ground. Canadian Geotech J 39:1168-1180 